Working Paper in Economics No. 794

\title{
Optimal fuel taxation with suboptimal health choices
}

Simona Sulikova, Inge van den Bijgaart, David Klenert, Linus Mattauch

Department of Economics, October 2020 


\title{
Optimal fuel taxation with suboptimal health choices
}

\author{
Simona Sulikova Inge van den Bijgaart David Klenert \\ Linus Mattauch*
}

October 16, 2020

\begin{abstract}
Transport has a large number of significant externalities including carbon emissions, air pollution, accidents, and congestion. Active travel such as cycling and walking can reduce these externalities. Moreover, public health research has identified additional social gains from active travel due to health benefits of increased physical exercise. In fact, on a per mile basis, these benefits dominate the external social costs from car use by two orders of magnitude. We introduce health benefits and active travel options into an optimal taxation model of transport externalities to study appropriate policy responses. We characterise the optimal second-best fuel tax analytically: when physical exercise is considered welfare-enhancing, the optimal fuel tax increases. Under central parameter assumptions it rises by $49 \%$ in the US and $36 \%$ in the UK. This is due to the low fuel price elasticity of active travel. We argue that fuel taxes should be implemented jointly with other policies aimed at increasing the uptake of active travel to reap its full health benefits.
\end{abstract}

Keywords: Transport Externalities; Congestion; Active travel; Fuel; Health Behaviour; Optimal Taxation

JEL Codes: H23, I12, Q58

\footnotetext{
*Sulikova: University of Oxford, simona.sulikova@ouce.ox.ac.uk. van den Bijgaart: University of Gothenburg, inge.van.den.bijgaart@gu.se. Klenert: Joint Research Centre, European Commission, david.klenert@ec.europa.eu. Mattauch: University of Oxford, linus.mattauch@inet.ox.ac.uk. We thank seminar audiences in Berlin, Oxford, ISER Osaka, at EAERE, IIPF and Elizabeth Baldwin, Geir Bjertnaes, Christian Brand, Bart DeFloor, Felix Creutzig, Marc Fleurbaey, Franziska Funke, Reyer Gerlagh, Cameron Hepburn, Zarko Kalamov, Sebastian Kraus, Ian Parry, Ryan Rafaty, Gregor Schwerhoff and Jiaxin Zhao for helpful comments.
} 


\section{Introduction}

Transport policies need to balance the economic gains from vehicle use with a large number of significant externalities, including air pollution, accidents, congestion, and climate change. For example, in the US, UK, and France, the transport sector is now the largest contributor of greenhouse-gas emissions (Hockstad and Hanel, 2018; Gabbatiss, 2018; Lepoutre, 2018). Increased active travel such as cycling and walking - even to the nearest public transport stop - can reduce these externalities, especially in urban areas. An additional benefit from active travel is that physical exercise is beneficial for health, especially given high rates of inactivity and obesity in many populations. Previous scenario-based modelling in public health has indicated that the health benefits from active travel due to increased exercise are larger than the benefits from abating emissions and air pollution of private vehicles (Woodcock et al., 2009; Maizlish et al., 2017; Wolkinger et al., 2018; De Hartog et al., 2010). For example, Woodcock et al. (2009) find that an increased active travel scenario would avoid 530 premature deaths per million population in London annually, while a lower-carbon-emission motor vehicles scenario would only save 17 through lower air pollution exposure.

Surprisingly, economists have yet to examine the significance of these health benefits from active travel for optimal regulation of urban transport. Many citizens are not aware of the full health benefits exercise provides (Fredriksson et al., 2018; San Diego and Merz, 2020). For instance, the effectiveness of simple interventions such as reminders to go to the gym (Calzolari and Nardotto, 2017), initial payments (Charness and Gneezy, 2009), and evidence of overspending on gym contracts (DellaVigna and Malmendier, 2006) point to self-control problems and an underappreciation of the health benefits of exercise, especially before they materialise. Therefore, the health benefits of active travel make passenger transport an unexamined case of a "behavioural-environmental second-best problem" (Shogren and Taylor, 2008). It is, however, yet to be determined whether instruments such as fuel taxes are appropriate to reap the health benefits from 
increased active travel in addition to mitigating the externalities of car use.

In this article, we examine a novel economic effect by adding an active travel mode to a model of transport externalities from car use. Households respond to higher fuel taxes by buying more fuel-efficient cars and reducing car travel, and additionally shift to alternative models of travel that involve exercise, such as walking or cycling. However, they do not fully internalize that they get healthier by adopting such active modes of travel travelling. We confirm that, on a per mile basis, the monetary value of the health benefits from active travel exceeds the social costs of unregulated externalities of carbon emissions, air pollution, congestion, and accidents by two orders of magnitude. Any first-best policy would thus involve a large subsidy to promote active travel. In the absence of such subsidies, we derive the optimal second-best fuel tax that corrects for the externalities and the unrealised health benefits. We examine the difference for the tax rule and quantify the appropriate tax rate both including, and excluding health benefits from active travel.

Importantly, we find that the optimal tax increases by $49 \%$ in the US and $36 \%$ in the UK when health benefits from physical exercise are included. The second-best optimal fuel tax for the US is $\$ 10.13 /$ gal, and $\$ 6.81 /$ gal without physical inactivity costs, while the current rate in the US is $\$ 0.55 /$ gal (American Petroleum Institute, 2020). The optimal fuel tax for the UK is $\$ 4.54 /$ gal, which is somewhat higher than the current rate of $\$ 4.06 /$ gal (RAC, 2020). Without physical activity costs, the optimal second-best tax would be $\$ 3.35 /$ gal.

Previous work established that the external costs of transport are not fully reflected in fuel price; fuel taxes are inefficiently low in most European countries (Santos, 2017), and US states. ${ }^{1}$ Accounting for the physical health benefits from active travel thus further increases the gap between actual and optimal fuel taxes. Our sensitivity analysis shows that the optimal second-best tax varies significantly within the range of realistic

\footnotetext{
${ }^{1}$ An exception is Parry and Small (2005), who claim that UK fuel taxes are too high.
} 
parameter values, from $\$ 6 /$ gal to $\$ 13 /$ gal for the US, and from $\$ 3.75 /$ gal to $\$ 7 /$ gal for the UK. Hence, neither the UK nor the US current fuel taxes likely exceed the optimal rate. Varying the Social Cost of Carbon (SCC) results in a range of $\$ 9.73-14.3 /$ gal for the US, and $\$ 4.03-8.12 /$ gal for the UK. Varying the physical inactivity cost results in a range of $\$ 8.80-11.72 /$ gal in the US, and $\$ 4.31-7.60 /$ gal for the UK.

On a per mile basis, physical inactivity represents the largest social cost of motorised private transport. Nevertheless, the "active travel adjustment" of the optimal fuel tax is comparatively small: a fuel tax is a fairly inefficient instrument to address these high costs because the uptake of active travel is not highly responsive to fuel price. A greater responsiveness of active travel to fuel taxation would increase the optimal tax adjustment. Indeed, it is often claimed in urban planning and transportation research that pricing car use should be complemented with infrastructure re-development to deliver feasible and effective transport solutions (Banister, 2008; Pucher et al., 2010; Buehler et al., 2017). The broader insight from our article is therefore that, when it is acknowledged that individuals' health decisions are not always welfare-maximising, this conclusion is supported from an economic point of view.

This manuscript builds on three distinct strands of literature: First, a large body of literature studies optimal levels of fuel taxes, and which externalities should be addressed by them (van Essen et al., 2019; Sansom et al., 2001). In addition to generating government revenue, fuel taxes are typically used for the purpose of reducing most forms of non-priced costs of transport, e.g. the externalities of carbon dioxide and particulate matter, or reducing congestion by raising the cost of driving. Parry and Small (2005) derive the optimal gasoline taxes for the US and Britain, accounting for congestion, accidents, carbon emissions and air pollution, and Antón-Sarabia and Hernández-Trillo (2014) apply it to Mexico. Sterner (2012) compares the optimality of fuel taxes in Europe and US, West and Williams III (2007) estimate an optimal fuel tax and its influence on labour supply in the US, and Hirte and Tscharaktschiew 
(2015) compare the fuel tax composition across US states and cities. Fuel taxes vary considerably between countries. In 2017, the fuel tax raised on a gallon of unleaded gasoline in the US was $\$ 0.55$, and $\$ 3.75$ in the UK (American Petroleum Institute, 2020; RAC, 2020). ${ }^{2}$ Yet, the optimal fuel tax literature has so far not considered the health benefits from active travel.

Second, the field of public health, starting with Woodcock et al. (2009), has identified high social benefits from active travel over and above the benefits from abating emissions and air pollution of private vehicles (De Hartog et al., 2010; Rabl and De Nazelle, 2012; Wolkinger et al., 2018). To the majority of the population, increasing physical activity outweighs the negative impacts of increased exposure to air pollution (Tainio et al. (2016), Mueller et al. (2015)). This is due to the overwhelmingly sedentary lifestyles that people in both the UK and US lead, making physical inactivity a leading risk factor for 6 of the 10 largest causes of death worldwide (WHO, 2018). Most UK adults do not exercise regularly (37\% never, $16 \%$ less than once a week, 57\% admit they never do activity strenuous enough to be out of breath, Eurobarometer 2018). This leads to significant costs including higher rates of disease incidence, lower quality of life, loss of income, excess healthcare costs, and productivity losses in the workplace. We build on the valuation methods in public health to quantify the welfare cost of travel that is inactive. The social costs of inactivity can be derived from quantifying the health benefits of physical activity and the value of a statistical life, once it is acknowledged that inactive citizens impose a cost on themselves.

Third, behavioural public economics research has elaborated on the important role of "internalities" in various domains of public policy (Allcott and Sunstein, 2015). An "internality" occurs when an individual imposes a significant cost on herself due to behavioural failures. ${ }^{3}$ As these private costs are imposed only or mainly on oneself

\footnotetext{
${ }^{2}$ For the UK, this is the sum of the fuel and the excise taxes. For the US this is the average over the different federal and state taxes.

${ }^{3}$ While this raises intricate issues on diverging normative positions about individual well-being, in this article we follow the treatment of "internalities" in recent behavioural public economics. An
} 
- which is true for lack of physical activity -, they fall outside the definition of an externality, which is a cost imposed on others. Nonetheless, governments regulate to increase welfare by reducing internalities, in cases where scientific evidence substantiates it. Internality taxes have been applied to the market for smoking (Gruber and Köszegi, 2004), gym memberships and exercise (in the form of subsidies, DellaVigna and Malmendier, 2006), sugary drinks (Allcott et al., 2019a; Allcott et al., 2019b) and the energy and automobile market (Allcott and Wozny, 2014; Allcott and Sunstein, 2015), where they also interact with environmental externalities. In the latter case, the interaction leads to a behavioural-environmental second-best problem (Shogren and Taylor, 2008). Chetty (2015), Bhargava and Loewenstein (2015), Allcott and Sunstein (2015), and Allcott et al. (2019b) all provide more extensive discussions of why regulating internalities is desirable, arguing that the complexity of choices people face, and large internal costs in e.g. health and energy efficiency, warrant the greater use of behavioural economics in regulation. Sin taxes, surcharges on prices of goods of which people consume too much because of internalities, have been modelled as either simple extensions of a Pigouvian tax (O'Donoghue and Rabin, 2006), or as complex interactions between taxes and individuals' heuristics and decisions, to achieve an optimal outcome in second-best settings (Allcott et al., 2014).

However, this body of literature has not considered the internality of physical inactivity in urban transport. Walking, cycling, and switching to public transport are considered ways in which people can achieve "appropriate" levels of physical activity as prescribed by public health guidelines (Watts et al., 2019; Gibson-Moore, 2019; OSG, 2015). The public health evidence supporting the health benefits of physical activity refers to it as a "miracle cure" (Davies et al., 2019) in the UK Chief Medical Officers' 2019 Physical Activity Guidelines. Meeting the minimum recommendations

alternative normative viewpoint, which we are not assessing in this article, would be to evaluate how urban transport policy is conducive to improving health, which seems predominant in the public health assessments we build on. For what could lead to different welfare evaluations of behavioural failures see Crisp, 2017; Fleurbaey and Blanchet, 2013; Mattauch and Hepburn, 2016. 
of 150 minutes of moderate-intensity physical activity per week has significant health benefits, which include reduced risk of cognitive impairment and dementia (Loprinzi et al., 2018), almost halving the risk of depression (Catalan-Matamoros et al., 2016), a $6 \%$ reduction in the risk of hypertension (Liu et al., 2017), a reduction in the risk of type 2 diabetes (Smith et al., 2016), cardiovascular disease, as well as higher bone mineral density (Onambele-Pearson et al., 2019). This is true even for exercise carried out in areas with elevated pollution levels (Tainio et al., 2016). It is well-known that people under-value the contribution of physical exercise to their long-term health (Zamir and Teichman, 2014). Even when citizens are aware of the health benefits from exercise, they most often claim not to have the time for it or not be interested in it (Eurobarometer, 2018). This reinforces the case for building active travel into their commuting routines. Similar to Allcott et al. (2019b), one can identify two behavioural biases influencing people's decisions not to exercise sufficiently: imperfect information and insufficient self-control. These lead to insufficient levels of exercise and further health impacts. ${ }^{4}$

Our contribution to the literature is threefold: First, and most importantly, we introduce a physical activity-related health internality into an established framework of transport decisions (Parry and Small, 2005), and use this behavioural-environmental framework to provide an analytical solution for the optimal second-best fuel tax. Second, we provide an updated quantification of the external costs of travel provided by Parry and Small (2005), considering recent research and global climate policy goals, and complement this with a quantification of the health benefits of active travel. For example, updating the carbon price estimates increases the contribution of fuel pollution to the optimal fuel tax by an order of magnitude; conversely, the relative contribution of

\footnotetext{
${ }^{4}$ Allcott et al. (2019a), Handel and Kolstad (2015) and Bronnenberg et al. (2013) all follow a similar set-up. Allcott et al. (2019a) describe their approach as one where they assume a hypothetical "counterfactual normative consumer," who has a sophisticated level of knowledge and no self-control problem, and assume that only their choices are welfare relevant. For the case at hand, this would translate to an individual who knows about the health benefits of physical activity and has sufficient self-control to exercise. Given enough time, she thus would carry out at least the minimum weekly recommended amounts of exercise according to WHO guidelines.
} 
air pollutants to the fuel tax falls. Third, in terms of policy implications, we contribute to evaluating the potential use of a fuel tax as opposed to other travel management policies. We confirm that raising the propensity of consumers to switch to active travel modes can greatly impact the appropriate fuel tax: the demand for vehicle miles travelled (VMT) is so inelastic that increasing appropriate elasticities to their upper bound found in the literature raises the fuel tax by up to $62 \%$ for the UK and $155 \%$ for the US. ${ }^{5}$

With increasing congestion, air pollution, and awareness of climate change, a number of cities worldwide have declared zero emissions zones, congestion charges, number-plate policies, or bans of certain types of vehicles in inner city areas - but while such local policies are attractive for addressing specific transport externalities, we focus on fuel taxes as they have some distinct advantages. First, since most countries already have fuel taxes in place and levels would only have to be adjusted accordingly, they can be implemented with relatively small administrative costs compared to infrastructure subsidies, physical exercise subsidies, or congestion fees. Second, fuel taxes and pricing instruments have a proven track record of reducing carbon emissions (Brand et al., 2013; Bretschger and Grieg, 2020; OECD, 2019; Sterner, 2012). Third, they generate government revenue, which could be used either for green spending on projects that further reduce emissions, including in low-carbon transport infrastructure, or for compensating low- and middle-income households that are especially affected by the tax. Both measures could make the public more supportive of fuel taxation (Klenert et al., 2018).

The remainder of the paper is organised as follows. Section 2 describes the model, and our analytical result for the optimal fuel tax. Section 3 explains our choice of parameterisation. Section 4 presents the quantitative results and Section 5 discusses

\footnotetext{
${ }^{5}$ It may be argued that, especially in the US case, realising such an increase is politically unrealistic in the foreseeable future. Still, our result indicates that current fuel tax rates are further below their preferred levels than previously thought, which, as we discuss in Subsection 4.2, implies fuel tax increases have greater benefits.
} 
the policy implications. Section 6 concludes.

\section{Analytical Framework}

\subsection{Model}

To explore how the fuel tax might be optimally adjusted to account for health benefits of public transport, we consider a stylised framework of travel decisions. We take advantage of the fact that in certain settings, internalities can be treated as extensions of externalities (O'Donoghue and Rabin, 2006). This allows us to base our framework on Parry and Small (2005), and extend it to account for active travel decisions and associated health benefits.

We consider a representative agent with the utility function

$$
U=u\left(\psi\left(C, M, T^{i n}, T^{a c}, G\right), N\right)-\varphi(P)-\delta(A)+\xi(Q)
$$

where $C$ is the quantity of numeraire consumption, $M$ total distance travelled, $T^{i n}$ and $T^{a c}$ is total time travelled using active and inactive modes respectively, $G$ exogenous government spending, and $N$ leisure, with $U_{C}, U_{M}, U_{G}, U_{N}>0$, and $U_{T^{i n}}$ and $U_{T^{a c}}<0$, with the subscript denoting a partial derivative. The level of pollution is denoted by $P, A$ captures accidents, and health is denoted by $Q$. As Parry and Small (2005), we assume $u(\cdot)$ and $\psi(\cdot)$ are quasi-concave, and $\varphi(\cdot)$ and $\delta(\cdot)$ are convex. The functions $\varphi(\cdot)$ and $\delta(\cdot)$ capture the dis-utility from pollution and accidents, respectively. We add the concave function $\xi(\cdot)$, which captures the positive utility from health $Q .{ }^{6}$

Total travel $M$ can be separated into two components, inactive travel $M^{\text {in }}$ and active travel $M^{a c}$.

$$
M=M^{i n}+M^{a c} .
$$

\footnotetext{
${ }^{6}$ Equation (1) models the utility from health and leisure as separable. As a consequence, any improvement in health will leave the labour-leisure trade-off unaffected.
} 
Inactive travel denotes travel using modes that require very little physical activity, most importantly using the car. Active travel instead captures walking and cycling. We also consider public transport as an active mode of travel, as it typically requires the individual to walk or bike to the bus stop, tram stop, or train station (Rissel et al., 2012 ), in some cases providing up to $30 \%$ of daily exercise recommendations (Besser and Dannenberg, 2005). As such, active travel requires spending $S$, which will be further specified below. Inactive travel distance $M^{\text {in }}$ requires fuel $F$ and other travel inputs $H: M^{i n}=\chi(F, H)$. In line with Parry and Small (2005), we assume that $M^{i n}$ is homogeneous of degree one with respect to its inputs. This specification allows for multiple channels of substitution. For instance, as fuel prices increase, the consumer can decide to i) reduce total distance travelled, $M$, ii) spend more on other inactive travel inputs, $H$, such as purchasing a vehicle with higher fuel economy, or iii) increase active travel distance, $M^{a c}$.

The agent spends time $T^{i n}$ in inactive travel. For a given distance $M^{i n}$, this time is increasing in the amount of congestion on roads, which we take as an increasing function of the population average inactive miles travelled, $\bar{M}^{i n}$ :

$$
T^{i n}=\pi^{i n}\left(\bar{M}^{i n}\right) M^{i n}
$$

where $\pi_{M^{i n}}^{i n}>0$, with the subscript denoting a partial derivative, and the bar indicating that we consider a population average. $\pi^{i n}$ is equal to the inverse of speed of inactive travel, which we assume the agent takes as exogenous. In equilibrium, $\bar{M}^{i n}=M^{i n}$. For active travel we abstract from congestion, ${ }^{7}$ and model time travelled as directly proportional to distance:

$$
T^{a c}=\pi^{a c} M^{a c}
$$

with $\pi^{a c}$ the inverse of speed from active mobility. Only inactive travel contributes to

\footnotetext{
${ }^{7}$ Even though public transport can get congested, this does not typically increase travel time. Bicycle paths do not generally get congested to the extent that travel time increases.
} 
pollution, both in the form of carbon dioxide emissions, and local air pollution. $\mathrm{CO}_{2}$ emissions are directly proportional to fuel use. To capture local air pollution effects, inactive miles travelled offer a better proxy (Hitchcock et al., 2014). ${ }^{8}$ This allows us to write

$$
P=P^{f}(\bar{F})+P^{m}\left(\bar{M}^{i n}\right),
$$

with $P_{\bar{F}}^{f}>0$ and $P_{\bar{M}^{i n}}^{m}>0$. Similar to congestion, we assume the agent will take pollution as given; she will not internalise the effect of travel decisions on the population averages $\bar{F}$ and $\bar{M}^{i n}$.

Both active and inactive travel are subject to accident risk. We separate accident costs associated to active and inactive travel. For inactive travel, accident costs are increasing with the amount of travel. As travel increases, the agent also imposes an "accident externality" upon other users: the higher average travel, $\bar{M}^{i n}$, the more likely a road user will be involved in an accident. For active travel, we similarly assume that higher travel increases the number of, and thereby costs of, accidents. Yet, roads that are busier with cars tend to be more dangerous to both cyclists and pedestrians. Conversely, there exists a so-called "safety in numbers" effect: more cyclists on the road tend to make cycling safer overall (Elvik and Bjørnskau (2017), Kahlmeier et al. (2017)). Hence, we assume that the accident costs associated with active travel are increasing in the average amount of inactive travel, $\bar{M}^{i n}$, and decreasing in average active travel, $\bar{M}^{a c}$. This gives

$$
A=A^{i n}\left(M^{i n}, \bar{M}^{i n}\right)+A^{a c}\left(M^{a c}, \bar{M}^{i n}, \bar{M}^{a c}\right),
$$

with $A_{M^{i n}}^{i n}>0$ and $A_{\bar{M}^{i n}}^{i n}>0$. Likewise, $A_{M^{a c}}^{a c}>0$, and $A_{\bar{M}^{i n}}^{a c}>0$, while $A_{\bar{M}^{a c}}^{a c}<0$.

We assume active travel is conducive to health. To capture this we write health as

\footnotetext{
${ }^{8}$ Substantial emissions of particulate matter from transport are due to tyre, brake, and road abrasion, rather than fuel consumption. Fuel emissions contribute mostly to noxious gas emissions such as $\mathrm{NO}_{x}$ and ozone.
} 
a function of active travel:

$$
Q=Q\left(M^{a c}, O\right)
$$

where $O$ are other forms of exercise, ${ }^{9}$ with $Q_{M^{a c}}>0$ and $Q_{O}>0$. We assume that the agent considers only a constant share $\omega \in[0,1]$ of $Q$ as relevant in her optimisation problem. More specifically, instead of considering actual health $Q$, she considers "perceived health", $Q^{\text {per }}$

$$
Q^{p e r}=\omega Q+\tilde{Q}
$$

where the agent considers $\tilde{Q}$ as outside of her control, while in reality, $\tilde{Q}=(1-\omega) Q$. Whenever $\omega<1$, (8) represents the notion that the individual underestimates the effect of exercise on health. This underestimation is consistent with substantive evidence that individuals do not fully appreciate the positive effects of activity-related health. ${ }^{10}$ If $\omega=0$, health is considered as fully exogenous and unaffected by exercise, while if $\omega=1$, the agent accurately perceives health and the corresponding benefits of active travel.

With Equation (8) we adopt a specification of limited attention proposed by DellaVigna (2009), which assumes that the benefit of completing travel (in active mode) is "visible", while the health benefit from active travel is "opaque". This seems justified as many citizens are largely unaware of the high health benefits of even short walks (Steinhilber, 2017; Fredriksson et al., 2018; Bennett et al., 2009). Alternatively, the unrealised health benefits from active travel could represent a case of time-inconsistent preferences (Laibson, 1997; O’Donoghue and Rabin, 1999), where citizens highly value their health, but repeatedly postpone undertaking exercise. DellaVigna and Malmendier (2006) find evidence for the latter in the case for exercise in gyms. This can be captured by an equivalent formulation of Equation (8) in our static model,

\footnotetext{
${ }^{9}$ Note that any adverse effect of pollution on health is already subsumed in $\varphi(P)$.

${ }^{10}$ Additionally, publicly financed healthcare systems and moral hazard in health insurance imply that individuals may not bear the full cost of unhealthy decisions.
} 
as the assumption of time-inconsistent preferences implies an activity level less than desirable in the long term is pursued at any point in time. This holds in the absence of commitment devices, which arguably do not exist for active travel.

The agent's budget constraint is given by

$$
C+\left(p^{f}+t^{f}\right) F+p^{h} H+p^{o} O+S=w\left(1-t^{l}\right) L,
$$

where $p^{f}+t^{f}$ is the consumer price of fuel, $p^{h}$ is the price of other inactive travel inputs, and $p^{o}$ is the price of other forms of exercise. In addition, active travel requires the consumer to spend on items such as a bicycle or public transport. We denote by $S$ any such spending on active travel (with normalised price), with $S=S\left(M^{a c}\right), S(0)=0$ and $S_{M^{a c}}>0$. Finally, we denote the gross wage rate by $w$, and the labour tax rate is given by $t^{l}$. The total amount of time available is given by $\bar{L}$, which is allocated to labour $L$, leisure, $N$, and time spent travelling $T^{i n}$ and $T^{a c}$, such that

$$
L+N+T^{i n}+T^{a c}=\bar{L} .
$$

In the remainder of this paper, we assume that all prices are exogenous and constant. The fuel tax $t^{f}$, will be set by the policymaker. The proceeds of the fuel tax will be used to fund government spending $G$. The labour tax will in turn be set such that the government budget constraint is binding:

$$
G=t^{f} F+t^{l} w L
$$

Throughout, we assume that there exists an unique and interior equilibrium, where the consumer chooses strictly positive levels of $C, F, H, M^{a c}, O$ and $L$, and that $G$ is such that $t^{l}>0$. 


\subsection{Second-Best Fuel Tax}

In the above setup, an increase in fuel use is associated with carbon emissions. Additionally, higher fuel use increases the number of miles travelled, which increases local pollution, and also congestion and accident risk. All these effects are not internalised by the representative consumer; she takes the level of pollution, speed of travel, and marginal accident risk as given. On their own, these externalities already justify the introduction of a positive "externality tax" on fuel. Such a tax will be welfare-improving, as it forces the agent to internalise (part of) the externality. In addition to the externalities, the framework also features an "internality": whenever $\omega<1$, the agent underestimates the extent to which higher levels of active travel deliver positive health benefits. Consequently, the choices of $M^{a c}$ and $O$, and resulting $Q$, may be suboptimally low.

Our aim is to quantify how the consideration of these health benefits of active travel affects the welfare-maximising (optimal) fuel tax. For this purpose, we derive

the solution for the optimal fuel tax, $t^{f *}$, and calibrate its value. We present the full derivation of $t^{f *}$ in Appendix A, where we obtain the following result:

$$
\begin{aligned}
t^{f *}=Z^{P_{\bar{F}}}+\left[Z^{P_{\bar{M}} i n}+Z^{C}\right. & \left.+Z^{A_{\bar{M}^{i n}}}\right]\left(\frac{-d M^{i n}}{d t^{f}} / \frac{-d F}{d t^{f}}\right)+Z^{A_{\bar{M}^{a c}}}\left(\frac{-d M^{a c}}{d t^{f}} / \frac{-d F}{d t^{f}}\right) \\
& -(1-\omega) \tilde{Z}^{Q}\left(\frac{-d Q}{d t^{f}} / \frac{-d F}{d t^{f}}\right)-w t^{l}\left(\frac{-d L}{d t^{f}} / \frac{-d F}{d t^{f}}\right) .
\end{aligned}
$$

Here we define

$$
Z^{P_{\bar{F}}} \equiv \frac{\varphi_{P}}{\mu_{I}} P_{\bar{F}}^{f} ; Z^{P_{\bar{M}^{i n}}} \equiv \frac{\varphi_{P}}{\mu_{I}} P_{\bar{M}^{i n}}^{m} ; Z^{C} \equiv \Gamma^{i n} \pi_{\bar{M}^{i n}}^{i n} M^{i n}
$$

and

$$
Z^{A_{\bar{M}^{i n}}} \equiv \frac{\delta_{A}}{\mu_{I}}\left[A_{\bar{M}^{i n}}^{i n}+A_{\bar{M}^{i n}}^{a c}\right] ; Z^{A_{\bar{M}^{a c}}} \equiv \frac{\delta_{A}}{\mu_{I}} A_{\bar{M}^{a c}}^{a c} ; \tilde{Z}^{Q} \equiv \frac{\xi_{Q}}{\mu_{I}}
$$

with $\Gamma^{i n} \equiv w\left(1-t^{l}\right)-\frac{\psi_{T i n}}{\psi_{C}}$. 
Equation (12) characterises the optimal fuel tax. This tax is equal to the sum of un-internalised costs associated with fuel use. The first term in (12), $Z^{P_{\bar{F}}}$, is the direct pollution externality of fuel use. It is equal to the marginal cost of pollution, $\varphi_{P}$, multiplied by the effect of additional fuel use on pollution, $P_{\bar{F}}^{f}$, and converted to consumption units using the shadow value of income, $\mu_{I}$.

Next, higher fuel use is associated with more inactive miles travelled. The term $Z^{P_{\bar{M}^{i n}}}+Z^{C}+Z^{A_{\bar{M}}^{i n}}$ captures the marginal externality cost of inactive miles travelled, with $Z^{P_{\bar{M}}^{i n}}, Z^{C}$ and $Z^{A_{\bar{M}}^{i n}}$ the cost associated with increased air pollution, congestion, and accidents, respectively. ${ }^{11}$ The contribution of these costs to the magnitude of the optimal fuel tax depends on the extent to which fuel taxes reduce miles travelled visà-vis fuel use. If the reduction in fuel use due to higher fuel taxes is associated with a small reduction in miles travelled (small $\left(\frac{-d M^{i n}}{d t^{f}} / \frac{-d F}{d t^{f}}\right)$ ), then only a small portion of the externality costs associated with miles travelled can (implicitly) be attributed to fuel use. Vice versa, if $\left(\frac{-d M^{i n}}{d t^{f}} / \frac{-d F}{d t^{f}}\right)$ is large, then the externality costs associated primarily with miles travelled greatly contribute to the magnitude of the optimal fuel tax.

Likewise, fuel taxes may lead to changes in active travel distance, which is associated with accident externalities, with cost $Z^{A_{\bar{M}}^{a c}}$. The contribution of those costs to the optimal fuel tax then depends on the relative response of active travel to fuel taxes: $\left(\frac{-d \bar{M}^{a c}}{d t^{f}} / \frac{-d F}{d t^{f}}\right)$

Our main effect of interest is $(1-\omega) \tilde{Z}^{Q}\left(\frac{d Q}{d t^{f}} / \frac{-d F}{d t^{f}}\right)$ : the adjustment of the optimal fuel tax to the health internality. $\tilde{Z}^{Q}$ is the marginal value of additional health, with $1-\omega$ the un-internalised portion, see sections 3.1.6 and 3.1.7. As can be seen from (12), a high value of $\tilde{Z}^{Q}$ does not automatically imply that, once health internalities are accounted for, the optimal fuel tax is adjusted much; this is only the case if the fuel tax is an effective tool to increase health $Q$. Following (7), fuel taxes can affect

\footnotetext{
${ }^{11}$ The term $\Gamma^{i n}$ in $Z^{C}$ captures the notion that congestion is costly for two reasons: it creates a direct disutility (see (1)) and reduces time available to allocate to labour (see (10)).
} 
health through two channels: by changing active travel $M^{a c}$, or through other forms of exercise $O$. In the remainder of this article, and consistent with the empirical literature (Martin et al., 2012), we will assume that the effect of fuel taxes on other forms of exercise $O$ is negligible. This implies we set $d O / d t_{f}=0$, and focus on changes in active travel as the primary channel through which fuel taxation affects health.

The interpretation of the final remaining term is similar. Fuel taxes may also affect labour supply. Even though the agent takes into account that higher labour supply increases income, she does not internalise the positive effect of increased labour on the government budget. This effect is equal to the wage, multiplied by the labour tax rate, $w t^{l}$. The contribution of this effect to the optimal fuel tax is larger the larger the increase in labour supply in response to higher fuel taxes.

In the next section we quantify the optimal $t^{f}$ and the effect of considering the health benefits of active travel thereon. To facilitate this quantification, we further manipulate Equation (12) to

$t^{f *}=\frac{M E C}{1+M E B}+\frac{t^{l}\left(p^{f}+t^{f}\right)}{1-t^{l}} \frac{\varepsilon_{L L}^{c}\left(1-\eta^{M^{i n} I}\right)}{-\eta^{F F}}+\frac{t^{l}}{1-t^{l}}\left[\varepsilon_{L L}-\varepsilon_{L L}^{c}\left(1-\eta^{M^{i n} I}\right)\right] Z^{C} \beta^{M^{i n}} \frac{M^{i n}}{F}$,

with $\varepsilon_{L L}^{c}$ and $\varepsilon_{L L}$ the compensated and uncompensated labour supply elasticity. Akin to Parry and Small (2005), this optimal tax is separated in three components. The first component is the "adjusted Pigouvian tax," equal to the marginal external cost associated to fuel use, corrected by the marginal excess burden of labour taxation. The marginal external cost of fuel use is given by

$$
M E C \equiv Z^{P_{\bar{F}}}+\left[Z^{C}+Z^{A_{\bar{M}} i n}+Z^{P_{\bar{M}^{i n}}}\right] \beta^{M^{i n}} \frac{M^{i n}}{F}+\left[Z^{A_{\bar{M}^{a c}}}-(1-\omega) Z^{Q}\right] \beta^{M^{a c}} \frac{M^{a c}}{F}
$$

with $Z^{Q} \equiv \frac{\xi_{Q}}{\mu_{I}} Q_{M^{a c}}$ the marginal value of active travel through induced changes in health. We use the following ratios of fuel and income price elasticities to capture 
the indirect benefits of fuel taxes through inactive and active distance travelled and health ${ }^{12}$ :

$$
\beta^{M^{i n}} \equiv \frac{\eta^{M^{i n} F}}{\eta^{F F}} ; \beta^{M^{a c}} \equiv \frac{\eta^{M^{a c} F}}{\eta^{F F}}
$$

with $\eta^{X F}$ the fuel price elasticity of $X \in\left\{F, M^{i n}, M^{a c}\right\}$, and $\eta^{M^{i n}} I$ the income elasticity of inactive travel. The marginal excess burden $M E B$ is commonly defined as

$$
M E B \equiv \frac{\frac{t^{l}}{1-t^{l}} \varepsilon_{L L}}{1-\frac{t^{l}}{1-t^{l}} \varepsilon_{L L}} .
$$

The second component is the "Ramsey tax": fuel taxes raise revenues, which are used to finance government spending. This component commands a positive tax on fuel even in the absence of external costs. The third component is the "congestion feedback": a reduction in travel due to fuel taxation reducing congestion, freeing up time for labour. This creates a positive welfare effect as long as labour is taxed at a positive rate $\left(t^{l}>0\right)$, and as such increases the optimal fuel tax.

\section{$3 \quad$ Fuel tax components}

In this section we explain how we chose the parameter values for the quantification of the optimal fuel tax. We specify a central value and a plausible range. Table 1 summarises the main parameter values, and Figure 1 provides a graphical representation of the social costs. For comparability, where relevant, we adjust all values to year 2017 US dollar prices and US gallons. Finally, we state the implications for first-best policy.

In Figure 1, we converted $\mathrm{CO}_{2}$ emissions pollution per gallon into per mile units using baseline fuel efficiency as presented in Table 1, such that all social costs are expressed in per mile units. It shows that the per mile benefits of using an active mode

\footnotetext{
${ }^{12}$ The $\beta$ 's are equal to the response of miles travelled to fuel taxes relative to the response in fuel taxes. As such, they capture the relative effectiveness of fuel taxes in inducing changes in miles travelled, both active and inactive.
} 
Table 1: Parameter values used for optimal fuel tax calculation and sensitivity analyses

\begin{tabular}{|c|c|c|c|c|}
\hline \multirow[b]{2}{*}{ Parameter } & \multicolumn{2}{|c|}{$\overline{\mathrm{US}}$} & \multicolumn{2}{|c|}{ UK } \\
\hline & Central value & Range & Central value & Range \\
\hline Baseline fuel efficiency, $M^{i n, 0} / F^{0}$ & 24 & & 28 & \\
\hline Fuel pollution $\left(\mathrm{CO}_{2}\right)$, per gallon, $Z^{P_{\bar{F}}}$ & 91 & {$[41,405]$} & 86 & {$[38,380]$} \\
\hline Distance pollution (air), per mile, $Z^{P_{M}}$ & 4.5 & {$[1,9]$} & 3.6 & {$[1,8]$} \\
\hline Congestion, per mile, $Z^{C}$ & 10 & {$[3,14]$} & 5 & {$[0.1,7.3]$} \\
\hline Accidents, inactive, per mile, $Z^{A_{\bar{M}^{i n}}}$ & 6.4 & {$[2,18]$} & 1.6 & {$[1,2.3]$} \\
\hline Accidents, active, per mile, $Z^{A_{\bar{M}}^{a c}}$ & 5.3 & {$[1.5,15]$} & 1.6 & {$[1.2,2.6]$} \\
\hline Inactivity, per mile, $Z^{Q}$ & 691 & {$[403,999]$} & 244 & {$[146,683]$} \\
\hline Rate of health internalisation, $\omega$ & 0.5 & {$[0.3,0.7]$} & 0.5 & {$[0.3,0.7]$} \\
\hline Fuel price elasticity, $\eta^{F F}$ & -0.36 & {$[-0.21,-0.75]$} & -0.48 & {$[-0.3,-0.9]$} \\
\hline VMT-fuel price elasticity, $\eta^{M^{i n} F}$ & -0.25 & {$[-0.05,-0.3]$} & -0.35 & {$[-0.2,-0.5]$} \\
\hline Income elasticity of inactive travel, $\eta^{M^{i n} I}$ & 0.4 & {$[0.02,0.6]$} & 0.605 & {$[0.3,0.8]$} \\
\hline Cross-elasticity of active travel, $\eta^{M^{a c} F}$ & 0.18 & {$[0.17,0.25]$} & 0.18 & {$[0.17,0.25]$} \\
\hline Current tax rate on gasoline ${ }^{*}, t_{f}^{0}$ & 55 & n.a. & 406 & n.a. \\
\hline
\end{tabular}

*Includes VAT for the UK but not US, and is provided in US gallons. All values are provided in USD cents at end 2017 prices, using the end 2017 exchange rate $1 \mathrm{GBP}=1.351 \mathrm{USD} .=1.1251 \mathrm{EUR}$, and either per mile or per US gallon. $M^{i n, 0}$ and $F^{0}$ denote intensive miles travelled and fuel used at the initial gasoline tax rate. Entries in the upper half of the table correspond to the social costs of transport and justification for the values is given in subsections 3.1.2 through 3.1.7.

of travel are two orders of magnitude larger than most other social costs. This difference is partly due to the difference in time it takes to travel one mile by motor vehicle as opposed to travelling one mile by foot or by bicycle.

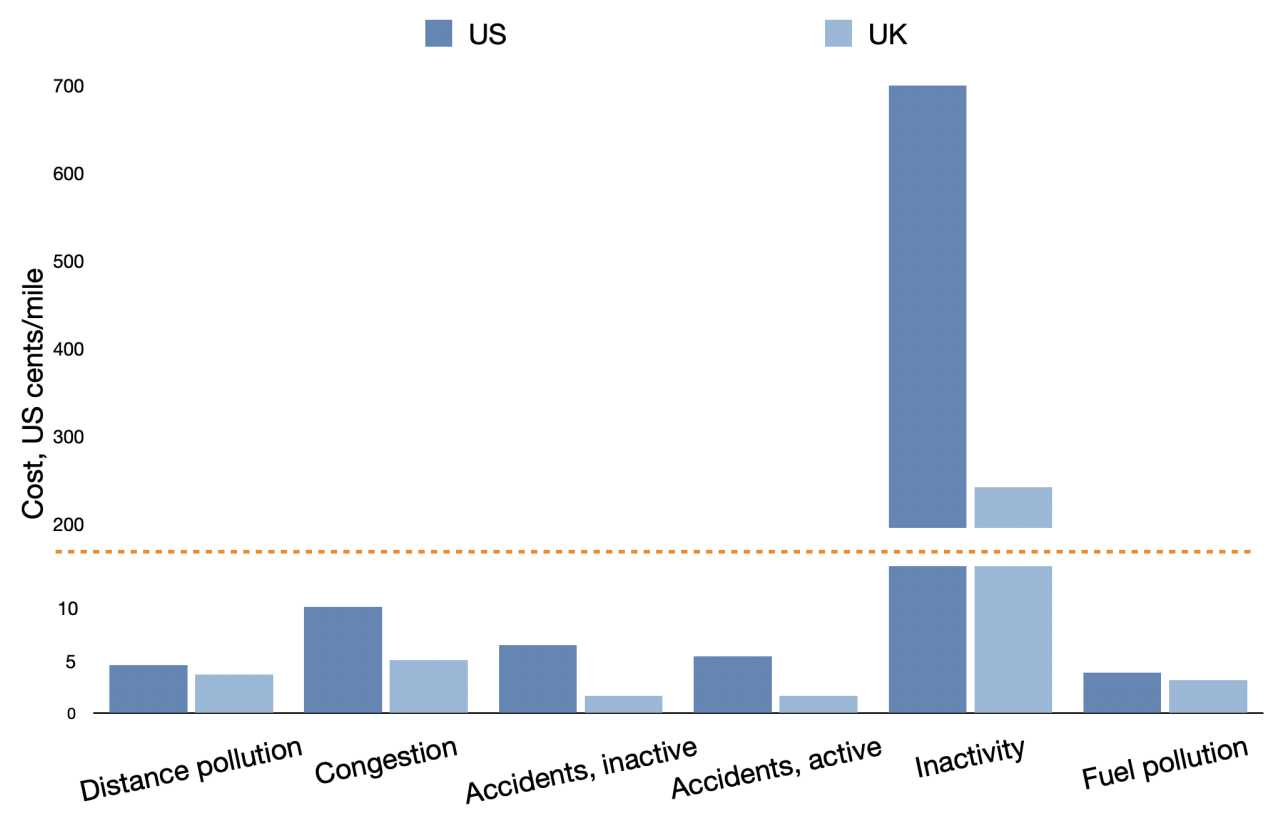

Figure 1: Social costs of personal car travel in US cents and on a per-mile basis. 


\subsection{Parameterisation}

\subsubsection{Baseline fuel efficiency and elasticities}

Baseline fuel efficiency The US average fuel efficiency was 24 miles/gallon in 2016 (Federal Highway Administration, 2018), which we use to parameterise the fuel efficiency at current tax levels, $M^{i n, 0} / F^{0}$. In the UK, fuel efficiency of personal cars is 28 miles/gallon (DfT, 2018b; DfT, 2018c). The difference in fuel efficiency is due to a smaller average size of the UK private vehicle fleet, and a higher proportion of diesel cars, which have a higher average fuel economy.

Fuel price elasticities Based on papers reviewed by Litman (2019), Dieler et al. (2015), and Litman (2013), we choose a fuel price elasticity, $\eta^{F F}$, of -0.38 for the US as a central estimate. This is slightly less elastic than the UK value of -0.45 , where wider public transit offers alternatives to car use. The elasticities of inactive miles travelled (VMT) with respect to fuel price, $\eta^{M^{i n}} F$, are calibrated at -0.25 in US, and -0.35 in the UK. ${ }^{13}$

To our knowledge, few direct estimates of the cross-elasticity of active travel (walking and cycling) with respect to the fuel price, $\eta^{M^{a c} F}$, exist. Instead, we primarily utilise estimates of the cross-elasticity of public transport with respect to fuel price (Blanchard, 2009; Lane, 2008; Maghelal, 2011). The use of public transit requires getting to and from stations, often done on foot or by an alternative active mode, and certain public transit investments have been found to be an effective way of increasing active travel (Reis et al., 2016). We adopt a range of $0.17-0.25$ for $\eta^{M^{a c} F}$, with a central value of 0.18 for both the US and the UK.

\footnotetext{
${ }^{13}$ The lower elasticity of miles travelled vis-à-vis fuel use is explained by the fact that the most significant response of an increase in fuel price is typically not reduction in the distance travelled by people, but rather upgrading to a higher fuel economy car (Coglianese et al., 2017).
} 
Income elasticity of inactive travel The elasticity of inactive travel demand with respect to income, $\eta^{M^{i n} I}$, is calibrated at $0.4(0.02-0.6)$ for the US, and $0.605(0.3-0.8)$ in the UK. This is more conservative than older estimates, which sometimes exceed unity (Graham and Glaister, 2002), and more aligned with newer estimates, such as Small, Van Dender, et al. (2007).

We use long-term elasticities where possible to allow for mode shifts and other behaviour changes. Further details and a full list of references on fuel price and income elasticities can be found in Appendix B.2.

Labour supply elasticities For the compensated and uncompensated labour supply elasticities, $\varepsilon_{L L}^{c}$ and $\varepsilon_{L L}$, we adopt the same values as Parry and Small (2005). These estimates fall in between the more recent estimates by e.g. Bargain et al. (2011) and Erosa et al. (2016).

\subsubsection{External cost of $\mathrm{CO}_{2}$ emissions (fuel pollution), $Z^{P_{\bar{F}}}$}

The external costs associated to fuel use are the cost of carbon emissions and associated climate damages. We derive our central estimate and range of plausible values from a large body of literature (see Appendix B.3 for a full overview). We multiply the value of climate change costs per tonne of $\mathrm{CO}_{2}$ emitted by the amount of $\mathrm{CO}_{2}$ emitted per gallon of fuel burnt, weighted by fuel type consumption in both countries (diesel/gasoline) to derive an average value of fuel pollution costs per gallon of fuel. ${ }^{14}$ With a social cost of carbon of $\$ 90 / \mathrm{tCO}_{2}$ and a range $\$ 40-400 / \mathrm{tCO}_{2}$, the central estimate for the US is 91 cents/gallon, with a range of 41-405 cents/gallon. The central estimate for the UK is 86 cents/gallon, with a range of 38-380 cents/gallon. Throughout, we abstract from any effects of fuel taxation on the cost of carbon.

\footnotetext{
${ }^{14}$ As fuel mix is almost exclusively gasoline in the US but approximately half and half gasoline and diesel in the UK, the marginal cost of climate damages per gallon of fuel is not the same in both countries.
} 


\subsubsection{External cost of air pollution (distance pollution), $Z^{P_{\bar{M}^{i n}}}$}

Local air pollution is caused by car tyre and break wear emissions of $\mathrm{PM}_{2.5}$ and $\mathrm{PM}_{10}$, which are approximately proportional to miles travelled (Grigoratos and Martini, 2014), and by gases from incomplete fuel combustion processes.

For the US, estimates of the cost of air pollution of about $\$ 0.03$ per vehicle mile travelled are considered reasonable (Mashayekh et al., 2011). ${ }^{15,16}$ The OECD (2015) report provides a high estimate of $\$ 0.089 / \mathrm{mile}$, and Parry et al. (2014) find a value of $\$ 0.06 /$ mile for all road transport. Conversely, a CGE analysis of the marginal damage of local pollutants emitted by all US economic sectors done by Muller et al. (2011) reveals cost of passenger road transport air pollution of only around $\$ 0.007 / \mathrm{mile}$. To reflect this uncertainty, we adopt values of $\$ 0.01, \$ 0.045$ and $\$ 0.09$ as the low, central, and high estimates for the US, respectively.

For the UK, national project evaluations use a value of $\$ 0.036 /$ mile (Hitchcock et al., 2014). The OECD (2015) report on transport air pollution costs based on a number of stated preference surveys yields a high value of $\$ 0.08 /$ mile travelled, while the average per-mile damage of air pollution for a passenger car in the EU is estimated at $\$ 0.009 /$ mile for gasoline and $\$ 0.033 /$ mile for diesel cars. Reflecting the $55-45 \%$ split between gasoline and diesel cars in the UK and updated costs of air pollution (Birchby et al., 2019), we adopt values of $\$ 0.01, \$ 0.036$ and $\$ 0.08$ as the low, central, and high estimates.

\subsubsection{External cost of congestion, $Z^{C}$}

Congestion is defined as the travel delay due to crowding of roads. Its cost is generally calculated using the value of time, typically proxied by the median hourly wage, extra

\footnotetext{
${ }^{15}$ Estimates are based on an analysis involving the 86 largest US metropolitan areas.

${ }^{16}$ Air pollution exposure is approximately the same for active and inactive modes of transport; cyclists and pedestrians breathe less filtered air, but often travel on a separate lane or road, meaning they breathe less contaminated air (de Nazelle et al., 2017).
} 
fuel expenditures, and the ratio of peak travel time compared to free-flow.

Ellis and Glover (2019) obtain a cost of congestion in the US of about $\$ 1,009$ per commuter $(\$ 0.08 /$ mile). We adopt the values by Inrix $(2018)$, who provide a central value of $\$ 0.1 /$ mile, and a range of $\$ 0.03$ - $\$ 0.14 /$ mile. In the UK, we follow Inrix (2019) and set the per-mile congestion costs at $\$ 0.05 /$ mile, with a lower and upper bound of $\$ 0.001 /$ mile and $\$ 0.073 /$ mile, respectively. ${ }^{17}$

\subsubsection{External cost of accidents, $Z^{A_{\bar{M}}{ }^{i n}}$ and $Z^{A_{\bar{M}}^{a c}}$}

There are two components to accident costs: the internalised cost of knowing and accounting for the risk of getting into a crash; and the external cost of the increased risk of causing an accident imposed on others by travelling. Hence, using the full cost of accidents per mile driven would overestimate the size of the accident externality. Instead, we adopt the approach by Lemp and Kockelman (2008), who estimate the external costs of transport in the US and assume that $50 \%$ of accident costs are external.

To determine the external cost of accidents associated to inactive travel, we consider all costs associated to car-on-car and car-on-pedestrian accidents, as well as $50 \%$ of the car-on-cyclist accident costs. Similarly for active travel, we include pedestrian only and cyclist-on-pedestrian accident costs and the remaining half of the car-on-cyclist accident costs. $^{18}$

Using accident data and cost estimates from the report by Blincoe et al. (2015), we find that accident costs attributable to inactive modes of transport, $Z^{A_{\bar{M}^{i n}}}$, amount to $\$ 0.064 /$ mile, with a range of $\$ 0.02-\$ 0.18 /$ mile for the US. Accident costs attributable to active modes of transport, $Z^{A_{\bar{M}}^{a c}}$ amount to $\$ 0.053 /$ mile, with a range of $\$ 0.015$ -

\footnotetext{
${ }^{17}$ Parry and Small (2005) already noted that the values available in empirical studies in transportation are VMT-weighted, but congestion costs enter the optimal fuel tax equation as being both VMT-weighted and fuel-price elasticity weighted. This is because demand for travel is more inelastic in more congested times and people internalise more of the waiting time cost. Adjusting for this reduces the marginal cost of congestion.

${ }^{18}$ In the US, many states legally assign collision fault to the motor vehicle, but some do not follow this rule, and in the UK collision fault is not automatically assigned to the driver. This is why we assign "blame" equally to both modes.
} 
$\$ 0.15 /$ mile. This is due to the proportionately higher death rate per accident and per mile travelled for active modes.

In the UK, $Z^{A_{\bar{M}}^{i n}}$ amounts to $\$ 0.015 /$ mile, with a range of $\$ 0.01-\$ 0.023 / \mathrm{mile}$. Accident costs attributable to active modes of transport, $Z^{A_{\bar{M}} a c}$, amount to $\$ 0.016 /$ mile as well, with a range of $\$ 0.012-\$ 0.026 /$ mile (DfT, 2018a). In order to arrive at the high estimate of accident costs, we used the WHO value of statistical life (VSL) to value the cost of a death or injury, instead of the UK Department for Transport values. ${ }^{19}$

\subsubsection{Cost of inactivity, $Z^{Q}$}

The health benefits of exercise are well-known to be the most substantial health-related impact of active travel, dwarfing air pollution or accident effects. For example, De Hartog et al. (2010) estimate that people shifting from car to bicycle for short trips (daily commute of 4.7 miles) lose 7 days of life due to traffic accidents, 21 days of life due to air pollution, but gain 8 months of life due to physical activity. Our analysis requires translating such benefits into monetary values.

Health benefits of exercise, or conversely the health costs of inactivity, are due to a number of different effects, listed in Figure 2. First and foremost, these health benefits comprise all mortality- and morbidity-reducing effects. Second, there may be productivity benefits, due to a reduction in absenteeism (taking sick leave), and presenteeism (being at work but having lower productivity due to illness). Third, greater health reduces the (public) health system costs. Depending on the characteristics of the health system (and the extent to which the individual bears the cost of absenteeism), the costs can be labelled as private or external. In the remainder of the analysis, we focus on the value of unrealised private health benefits only, as they are much larger than the direct productivity gains to the economy.

In order to calculate the marginal value of the private health benefits from physical

\footnotetext{
${ }^{19} \mathrm{VSL}$ is most commonly used in policy or investment appraisal in health, environment, and transport projects, and differs across disciplines.
} 


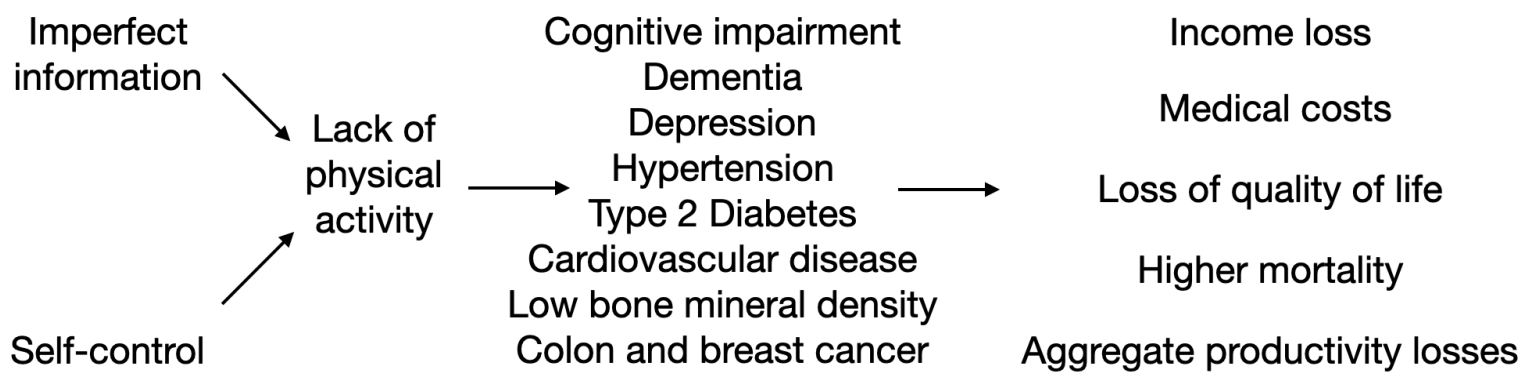

Figure 2: Some of the barriers to, and benefits of, physical activity.

activity for the UK and US, we used the Health Economic Assessment Tool (HEAT) developed by the World Health Organisation (Kahlmeier et al., 2017; Nieuwenhuijsen and Khreis, 2018). HEAT calculates the value of the changes in mortality arising from a specified change in walking and cycling for travel purposes. ${ }^{20}$

HEAT also requires inputs on the population considered, the baseline mortality rate per 100,000, and the relevant value of statistical life (VSL) with which to value the deaths avoided. ${ }^{21}$ The central value of VSL used for the US is $\$ 9.26$ million, with a range of \$5.4m-13.4 million (Moran and Monje, 2016). The central value of VSL for the UK is more conservative, $\$ 4.36$ million (WHO 2015), with a range of $\$ 2.2 \mathrm{~m}-12.6$ million (Thomas, 2020). HEAT assumes a linear relationship between exercise and health benefits for sedentary societies (Kahlmeier et al., 2017), meaning the baseline level of physical activity does not affect the marginal value of additional activity. Further details regarding the HEAT model, inputs and corresponding data sources can be found in Appendix B.4.

We converted the HEAT output to an estimate of the health benefit per mile of active travel. We obtained a central $Z^{Q}$ value of $\$ 6.91 /$ mile for the US, with a range of

\footnotetext{
${ }^{20} \mathrm{HEAT}$ is designed as an easy-to-use practitioner-oriented tool for health impact assessments. More complex health impact assessments would quantify the effect of exercise on morbidity as well as mortality. Our results are therefore likely to be conservative estimates of the health benefits of physical activity.

${ }^{21}$ In transport, environment, and medical fields, health is often quantified using stated or revealed preference methods, in order to arrive at the VSL. This method values everyone's life equally, regardless of their health or age.
} 
$\$ 4.03-9.99 / \mathrm{mile}$. For the UK, this value is $\$ 2.44 / \mathrm{mile}$, with a range of $\$ 1.46-6.83 / \mathrm{mile}$. The UK-US discrepancy has two sources: higher VSL estimates for the US, and higher US baseline mortality rates for younger members of the population.

\subsubsection{Rate of health internalisation, $\omega$}

The extent to which individuals are aware of the health benefits of exercise and active travel are captured by the parameter $\omega$. High numbers of respondents (50-85\%) in attitudinal transport surveys cite health reasons as one of their top three reasons for walking or cycling for travel (Useche et al., 2019; Fu and Farber, 2017; Börjesson and Eliasson, 2012; De Souza et al., 2014). However, in general exercise knowledge surveys, only about half of respondents are knowledgeable of the amounts of physical activity required for health, and about $20-30 \%$ are capable of identifying the approximate odds of developing diseases without physical activity (Fredriksson et al., 2018; San Diego and Merz, 2020; Bennett et al., 2009). We therefore chose a central value of 0.5 and a range of $0.3-0.7$ for $\omega$.

\subsection{Implications for first-best policy}

In the next section, we use the parameter values specified in Table 1 to quantify the optimal second-best fuel tax. Table 1, nonetheless, already permits a quantitative conclusion about first-best policy. In a first-best world, there exist appropriate policy instruments to address all market failures, as well as non-distortive (e.g.lump-sum) taxes to generate government revenues. One can verify that under these assumptions, the optimal carbon (fuel) tax is equal to the cost of fuel pollution, $Z^{P_{\bar{F}}}$. Similarly, the socially optimal level of the price instruments for all other externalities (and internality, by analogy) are at their respective Pigouvian levels. For the internality, this Pigouvian level is equal to the social cost of inactivity, multiplied by the uninternalised share (1- $\omega)$. Importantly, this means that, on a per mile basis, a first-best subsidy paid to 
individuals for incentivising active travel modes would be at a much higher level than any of the tax levels for the externalities, or indeed, the sum of all other externality taxes. ${ }^{22}$

\section{Quantitative Results}

\subsection{Optimal second-best fuel tax rates}

We use Equations (13)-(15) and the parameter estimates provided in Table 1 to calculate the optimal fuel tax. ${ }^{23}$ An increase in fuel taxation will reduce fuel use and inactive miles travelled, which will in turn affect the optimal tax through (14). To account for this, we follow Parry and Small (2005), and endogenise $F, M^{i n}$, and $M^{a c}$ in our numerical solution. Further details can be found in Appendix C.1.

We find an optimal fuel tax of $\$ 4.54$ /gallon of fuel in the UK, which is slightly higher than the current fuel tax. ${ }^{24}$ In the US, the optimal fuel tax amounts to $\$ 10.13 /$ gallon of fuel, which is more than ten times the current (population-weighted) average fuel tax across the fifty states. Table 2 lists the optimal tax levels and their decomposition. This decomposition shows that costs associated to congestion and physical inactivity are the main contributors to the fuel tax, albeit this is somewhat reduced due to the compensation for the marginal excess burden of labour taxation. Ramsey taxes are substantial, especially in the US; the congestion feedback does not significantly influence the optimal fuel tax rate.

Including physical activity increases the UK fuel tax by $36 \%$, and the US fuel tax by $49 \%$. Although this increase is significantly smaller than the pure per-mile social cost of physical inactivity, the inactivity component is still the largest contributor to

\footnotetext{
${ }^{22}$ For comparison to second-best see Section 4, and for the policy implications of that comparison see Section 5.

${ }^{23}$ We used $\mathrm{R}$ for all computations. Code available from authors on request.

${ }^{24}$ The total tax on UK fuel includes VAT (110 cents/gallon) and fuel duty (296 cents/gallon). In the United States, value added or indirect taxes are not levied on fuel.
} 
Table 2: Central calculations of the optimal fuel tax rate

\begin{tabular}{lrr}
\hline \hline Cost, USD cents/gallon & United States & United Kingdom \\
\hline Fuel efficiency, $M^{\text {in }} / F$ & 28.6 & 28.3 \\
Adjusted Pigouvian tax: & & \\
$\quad$ Pollution, fuel-related, $Z^{P_{\bar{F}}}$ & 91 & 86 \\
Pollution, distance-related, $Z^{P_{\bar{M}}^{i n}} \beta^{M^{i n}} M^{i n} / F$ & 90 & 74 \\
Congestion, $Z^{C} \beta^{M^{i n}} M^{i n} / F$ & 199 & 103 \\
Accidents inactive, $Z^{A_{\bar{M}}{ }^{i n}} \beta^{M^{i n}} M^{i n} / F$ & 127 & 33 \\
Accidents active, $Z^{A_{\bar{M}}^{a c}} \beta^{M^{a c}} M^{a c} / F$ & -4 & -1 \\
Physical inactivity, $(1-\omega) \beta^{M^{a c}} M^{a c} / F$ & 256 & 109 \\
Adjustment to $M E C$ for excess burden & -71 & -36 \\
Ramsey tax & 326 & 83 \\
Congestion feedback & -1 & 3 \\
\hline Optimal fuel tax rate with physical activity, $t_{1}^{f *}$ & $\mathbf{1 0 1 3}$ & $\mathbf{4 5 4}$ \\
Optimal fuel tax rate without physical activity & 681 & 335 \\
Naïve fuel tax rate & 593 & 372 \\
\hline Actual (2017) tax rate & 55 & 406 \\
\hline
\end{tabular}

Based on Equation (13) and (14), the optimal rate is the adjusted Pigouvian tax, adjustments for the excess burden, the Ramsey tax, and the congestion feedback, combined. The naïve rate is given by $\mathrm{MEC}_{F}$ (excluding the health internality) from Equation (14) with $M^{i n} / F=M^{i n, 0} / F^{0}$ and all $\beta$ 's equal to 1 .

the MEC part of the tax.

Consistent with both Parry and Small (2005) and Santos (2017), we find that the second largest externality component of the second-best optimal fuel tax for both countries is congestion. In London, congestion impacts are 28 times higher than the EU average (Cookson, 2016), which greatly influences the congestion costs for the UK, even though the value of travel time estimates for the US are higher than for the UK.

This is followed by inactive accidents in the United States. In the US, traffic accidents are associated with a far higher per-mile cost, even though the rates of traffic injuries are very similar in both countries. This is explained by a higher nominal value that is attached to human life in the US. Contrary to Parry and Small (2005), air pollution costs for both countries contribute less to the fuel tax than carbon emissions. This is the result of both increasingly stringent fuel air pollutant emissions standards, ${ }^{25}$

\footnotetext{
${ }^{25}$ Such as Corporate Average Fuel Economy (CAFE) standards.
} 
and growing consensus that the social cost of carbon is higher (see Subsection 3.1.2.

In addition to the second-best optimal tax, we compute "naïve" tax rates. This naïve rate is calculated using three assumptions. First, that our $\beta$ s are equal to 1; i.e., it assumes that both active and inactive miles travelled are equally responsive to fuel taxation as fuel use. Second, it ignores the feedback of tax-induced changes in fuel use and miles travelled to the tax rate. Third, the naïve rate abstracts from the interactions of the fuel tax with the labour tax, as well as the Ramsey component. Instead, the only relevant components to the tax are the external effects of car use. The naïve rate as such mimics common practice in transport and cost-benefit analysis evaluations. ${ }^{26}$ In our central calculations $\beta^{M^{i n}}=0.69(\mathrm{US})$ or $0.73(\mathrm{UK})$, and $\beta^{M^{a c}}=-0.50(\mathrm{US})$ and -0.38 (UK). The low $\eta^{M^{i n} F}$ reflects the very inelastic demand for vehicle-miles travelled (VMT), meaning that most reduction in fuel use comes from increases in fuel economy of driving and the vehicle fleet, not reductions in distances covered in cars. Thus, mileage-related externalities (air pollution, congestion, and accidents) are all inflated in the naïve fuel tax calculation.

Treating fuel efficiency, fuel consumption and distance travelled as endogenous, rather than exogenous, in the second-best optimal fuel tax calculation causes fuel consumption to fall by $43.9 \%$ and $3.7 \%$ in the US and UK, respectively. ${ }^{27}$ Inactive travel $M^{\text {in }}$ falls slightly less, by $33.1 \%$ in the US, and this is more than compensated for by an increase of $33.5 \%$ in active travel. In the UK, inactive travel also falls by less than fuel consumption, by $1.7 \%$. However, as active travel increases only by $1.4 \%$, total travel in the UK falls. The overall tax increases by $81.1 \%$ in the US and $3 \%$ in the UK. The change is more dramatic in the US because of the low fuel efficiency of

\footnotetext{
${ }^{26}$ In applied transportation research, the difference between the responsiveness of fuel consumption to fuel prices and miles travelled to fuel prices are often disregarded, and assumed to be unitary. Multiplying externalities only by fuel efficiency, and not by the responsiveness of VMT to fuel price, is considered the naïve approach in literature, and can sometimes lead to a doubling of the optimal fuel tax estimation (Newbery et al., 1995).

${ }^{27}$ Results for the second-best optimal fuel tax with these variables treated as fixed is presented in Appendix C.1, Table C.1.
} 
motor vehicles, and higher contingent valuation of people's time and lives, resulting in a bigger Pigouvian tax. In the UK, the current tax level is very close to the optimal level. The fuel efficiency of motor vehicles in the UK therefore does not change much in response to moving to the optimal level, and the endogenous solution does not change the optimum level significantly.

\subsection{Welfare Effects}

The welfare gain of implementing the second-best optimal fuel tax is presented in Table 3. We use the current tax rate as a benchmark, and consider a fuel tax that does, and does not, take into account active travel benefits. All gains are expressed as a share of current fuel expenditure. The analytical derivation of the welfare benefit is discussed in Appendix C.2. The welfare gain of implementing the second-best optimal tax that accounts for the health internality is $129 \%$ for the US, but only $0.16 \%$ for the UK. The net welfare gain in the UK is rather small, and becomes a loss either side of the optimal tax rate. In the US, any increase in the fuel tax yields significant welfare improvements. This difference is primarily due to the very low current US fuel tax, while the UK fuel tax is already close to the optimal rate.

We additionally present the changes in active and inactive miles travelled following the change in the fuel tax. In the UK, the small change in fuel taxes results in relatively small changes in distance travelled. In the US, however, the fuel price changes are large, and induce a substantial shift from inactive to active miles. ${ }^{28}$

Finally, we compute the effect of the tax increase on mortality through increased active travel. For this purpose, we use the HEAT tool (Kahlmeier et al., 2017), described in Section 3.1.6 and Appendix B.4. Increases in active travel primarily save lives by improving health from increasing exercise. HEAT then corrects this value for the

\footnotetext{
${ }^{28}$ However, as we used constant fuel price elasticities to calculate these changes, these results should be interpreted with caution. It is unlikely that a 20 -fold increase in the fuel tax in the US would induce the same rate of response as a $20 \%$ increase in the tax.
} 
Table 3: Welfare effects of fuel taxation

\begin{tabular}{lrrrrr}
\hline \hline \multirow{2}{*}{ Fuel tax } & \multicolumn{5}{c}{ US } \\
\cline { 2 - 6 } & Rate (c/gal) & Welfare change & $M^{\text {in }}$ change & $M^{a c}$ change & Annual lives \\
\hline$t^{f *}$ & 1013 & $129 \%$ & $-33.04 \%$ & $33.47 \%$ & 6266 saved \\
$t^{f}$, excluding health benefits & 681 & $124 \%$ & $-27.39 \%$ & $25.92 \%$ & 4701 saved \\
& & & & \\
Fuel tax type & \multicolumn{5}{c}{ UK } \\
\cline { 2 - 6 } & Rate (c/gal) & Welfare change & $M^{\text {in }}$ change & $M^{a c}$ change & Annual lives \\
\hline$t^{f *}$ & 454 & $0.16 \%$ & $-2.67 \%$ & $1.40 \%$ & 39 saved \\
$t^{f}$, excluding health benefits & 335 & $-0.99 \%$ & $4.58 \%$ & $-2.28 \%$ & 120 lost \\
\hline
\end{tabular}

Welfare changes are calculated relative to the current rate, and expressed as a percentage of current fuel expenditure, which is equal to approximately $\$ 1800$ in the US and $\$ 1500$ per person per year in the UK, according to household expenditure surveys (BLS, 2019; ONS, 2019). The current US fuel tax rate is $\$ 0.55 /$ gal, and the current UK fuel tax rate is $\$ 4.06 /$ gal.

lives lost due to greater air pollution exposure, and increase in accident fatalities of pedestrians and cyclists. ${ }^{29,30}$ Due to a larger tax increase and larger population size, lives saved are greatest in the US: setting the fuel tax at its optimal level saves 6266 lives each year.

\subsection{Sensitivity Analysis}

In Figures 3 and 4, we illustrate the sensitivity of the optimal second-best fuel tax with respect to each of the non-priced cost parameters and the elasticity parameters, keeping all other parameters at their central values (denoted X in the graphs). Further details and figures can be found in Appendix C.4.

For both the UK and US, the fuel tax is most sensitive to $\eta^{F F}$, the fuel price elasticity. This elasticity directly affects the optimal fuel tax through $\beta^{M^{i n}}$ and $\beta^{M^{a c}}$ in the MEC component (see (14)), and indirectly by governing the response of fuel use $F$ to the introduction of the fuel tax. Jointly, as shown in the figure, this results in a positive relationship between the fuel price elasticity and the optimal fuel tax. Using

\footnotetext{
${ }^{29}$ Further details regarding this computation can be found in Appendix C.3.

${ }^{30}$ HEAT only computes the lives saved due to an increase in active travel. Higher fuel taxation also reduces inactive miles travelled, which reduces air pollution and vehicle traffic fatalities. As we do not capture these effects, the values reported in Table 3 can be considered a lower bound for the lives saved due to the tax increase.
} 


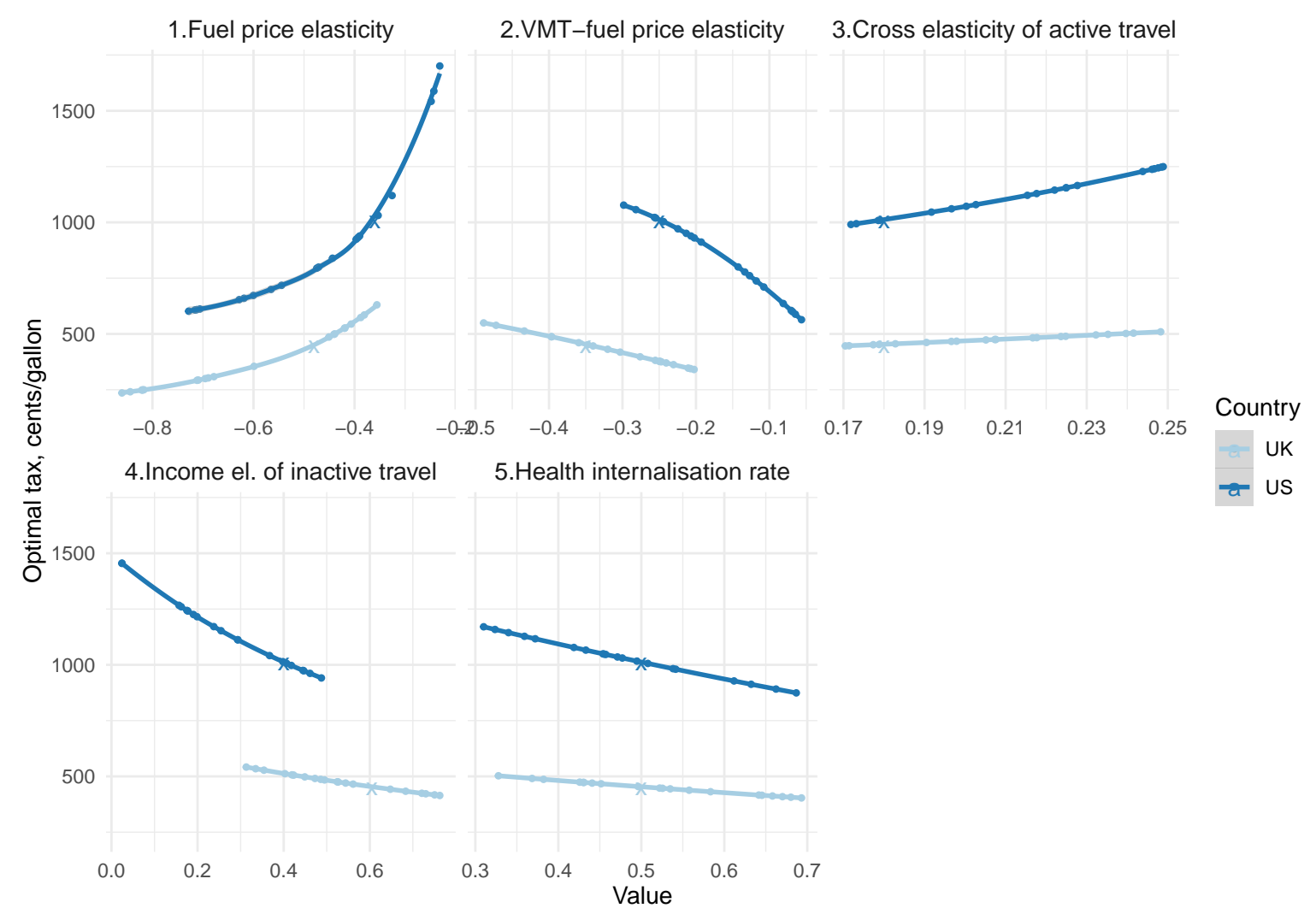

Figure 3: Sensitivity of the fuel tax to relevant elasticities and the rate of health internalisation

the upper or lower bound of the fuel price elasticity, as opposed to the central value, can either increase or decrease the fuel tax by as much as 50 percent. Conversely, the net effect of the elasticity of inactive travel (VMT) with respect to the fuel prices, $\eta^{M^{i n} F}$, on the fuel tax is negative. Using the upper bound instead of the central value for $\eta^{M^{i n} F}$, reduces the fuel tax by up to 50 percent; using the lower bound instead has a noticeably smaller effect. The fuel tax is relatively insensitive to the cross elasticity of active travel, $\eta^{M^{a c} F}$ and the rate of health internalisation. The income elasticity of inactive travel affects the fuel tax especially for the US. This effect materialises via the Ramsey tax component, which is comparatively large for the US to begin with (see Table 2).

Regarding social costs, the fuel tax is most sensitive to $Z^{P_{\bar{F}}}$, fuel pollution, i.e. the social cost of carbon. This is attributed to the fact that $Z^{P_{\bar{F}}}$ has a very high right-hand 


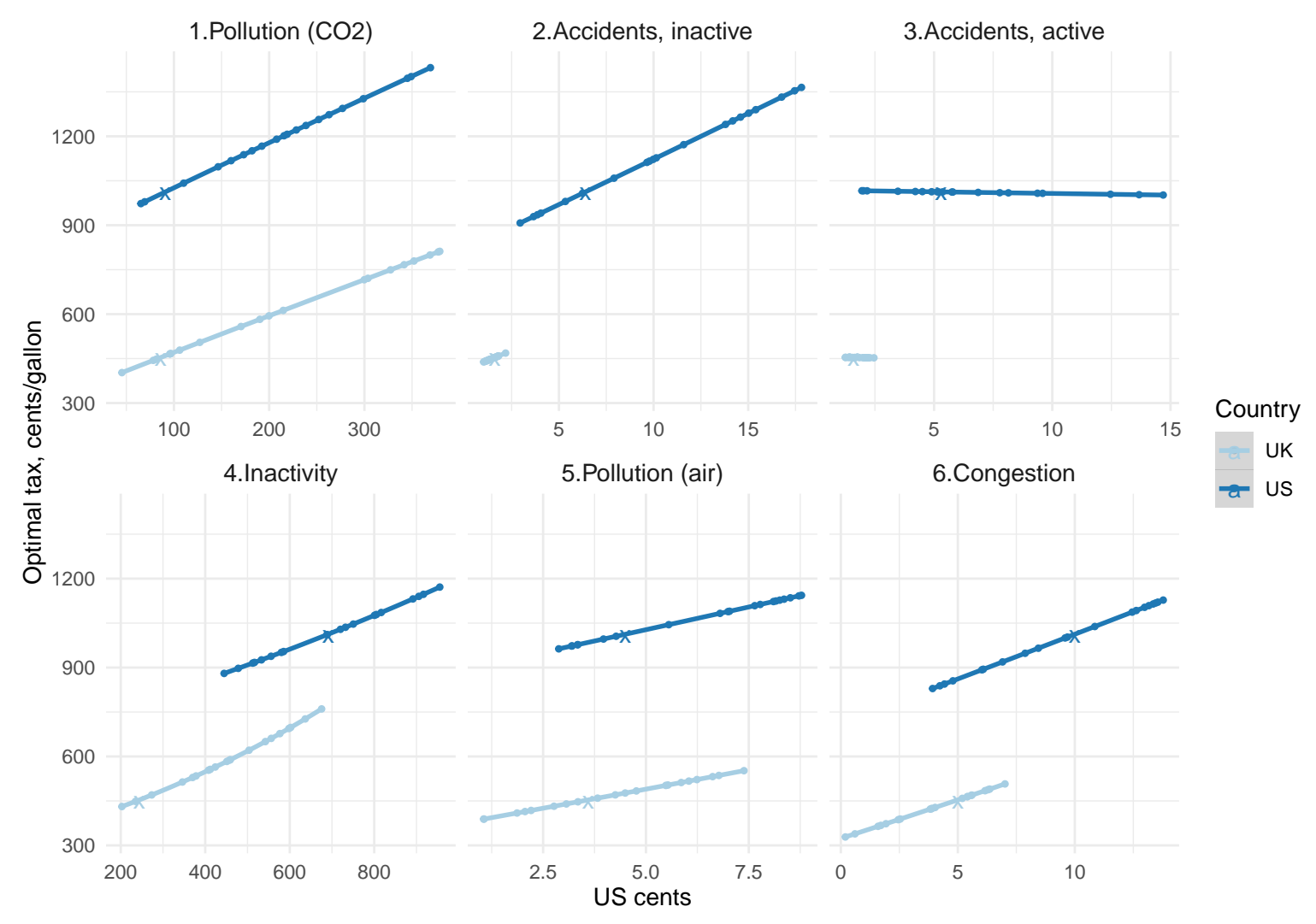

Figure 4: The sensitivity of the fuel tax to the social cost parameters.

tail, which follows from high estimates for the social cost of carbon under a businessas-usual scenario for global carbon emissions in the relevant literature (see also Table B.6 in Appendix B.3). Increasing $Z^{P_{\bar{F}}}$ to this upper bound increases the optimal fuel taxes by more than $\$ 4 /$ gal for both the UK and US. We find a similar sensitivity of the fuel tax to the calibration of $Z^{A_{\bar{M}} \text { in }}$ for the US, while the UK fuel tax increases by only a little when moving from the central value to the upper bound for $Z^{A_{\bar{M}}^{i n}}$.

Finally, the fuel tax shows similarly strong sensitivity to the remaining social cost parameters, with the exception of active accident costs, $Z^{A_{\bar{M}}^{a c}}$. Higher social costs $Z^{Q}$, $Z^{P_{\bar{M}}{ }^{i n}}$ and $Z^{C}$ result in higher levels of optimal fuel taxation, with the upper (lower) bound increasing the optimal fuel tax by around $\$ 1.50-2.50 /$ gal.

Figure 5 presents the results of a Latin Hypercube parameter sensitivity analysis using the pse package in R (Chalom and de Prado, 2015). We varied parameters for 
external costs and the elasticities using 20 values drawn at random from a uniform distribution, and allowed fuel use and mileage to be generated endogenously within the function. The function was run 200 times, with 50 bootstrap replicates. For the United States, the optimal fuel tax is less than $0.01 \%$ likely to be below the current 55 cents/gallon. For the UK, the optimal fuel tax is below current fuel tax of 406 cents/gallon with a $15 \%$ probability.

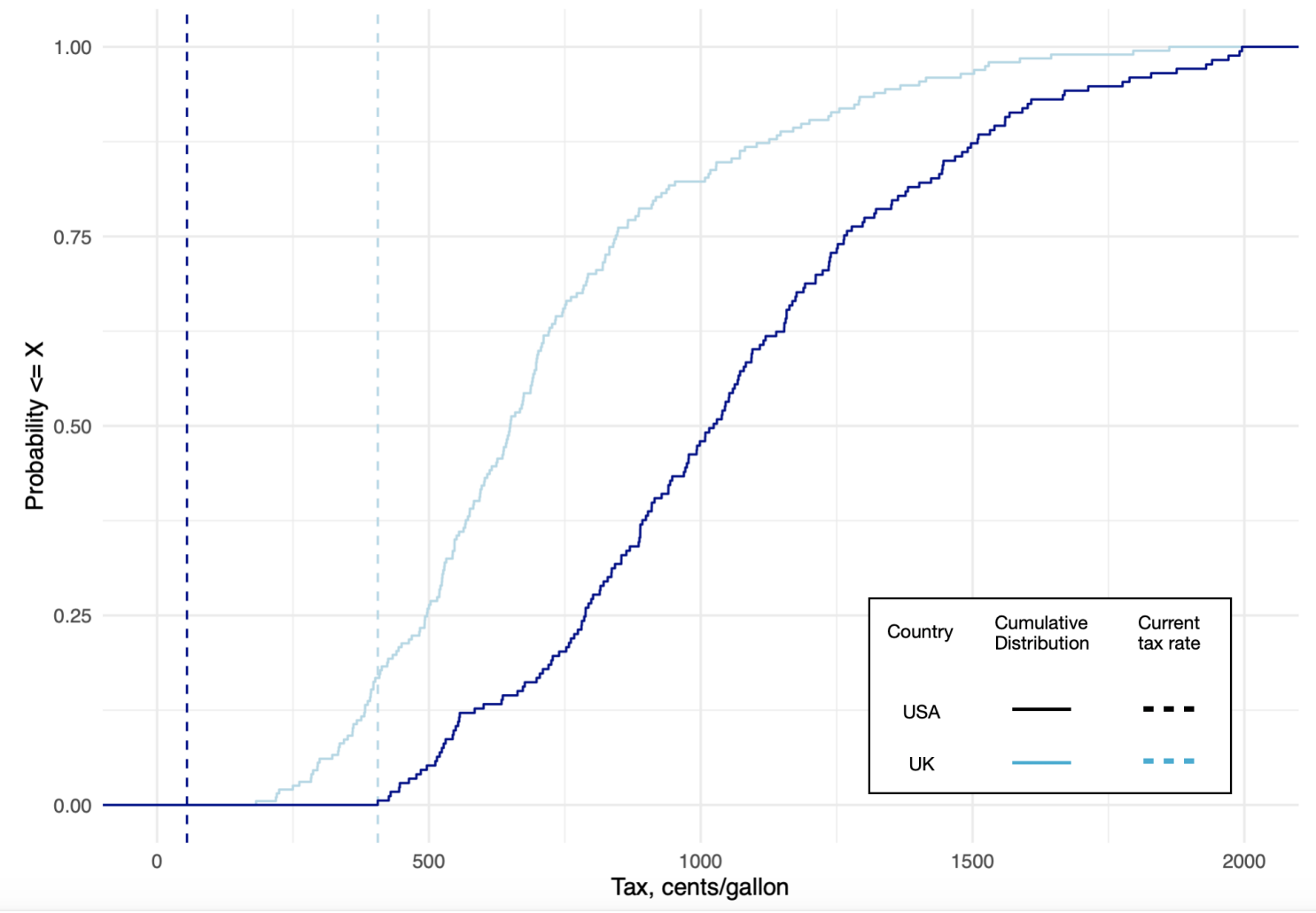

Figure 5: Cumulative distribution function of optimal fuel tax values for both US and UK.

\section{Discussion}

This article shows that it may be very costly to societies not to reap the health benefits from choosing travel modes that lead to more physical activity. Including these benefits in an analysis of optimal fuel taxation shows that the optimal fuel tax increases 
significantly, although to a lesser extent than one might expect based on assessments of the benefits of active travel measured in health. Here we discuss how our findings align with current thought on optimal transport policy, and subsequently discuss limitations of our approach.

Experts on urban transport policy have long argued for a mix of "push" and "pull" factors to efficiently reduce societal costs from car use (Pucher and Buehler, 2007; Creutzig and He, 2009; Sterner, 2012; Brand et al., 2013). "Push measures" discourage car use and include fuel or road pricing and parking fees; "pull measures" encourage uptake of other forms of transport by making them more attractive. Our study only explicitly considers a fuel tax, but a number of conclusions about other policy instruments may be drawn. First, both active and inactive miles travelled are relatively inelastic to the fuel tax. This not only affects the second-best optimal level, but also implies that a fuel tax on its own is not an ideal instrument for reducing mileage-related externalities. Parry and Small (2005) suggest that using a VMT tax for all externalities other than carbon emissions would be preferable where feasible. Indeed, there is renewed academic interest in alternative road pricing mechanisms, such as congestion or GPS-based charging, cordon pricing, optimal toll pricing, real time road pricing, or "superblocks" of pedestrian-only traffic (see Parry et al., 2007; Guo et al., 2017; Cramton et al., 2018; Bjertnæs, 2019; Mueller et al., 2019). However, ideal externality-correcting mechanisms have not been widely implemented and most plans to introduce congestion charging are advancing slowly (Reid, 2019). ${ }^{31}$ Still, the benefit of the fuel tax over a congestion charge is that a fuel tax can, at least indirectly, address all large externalities caused by driving concurrently, and be used to generate a broader revenue base for the government (Rietveld and van Woudenberg, 2005). It also encourages improvements in the fuel economy of the fleet by encouraging the purchase of

\footnotetext{
${ }^{31}$ Amongst the cities that are debating a congestion charge are Bath, Birmingham, Bristol, Cambridge, Cardiff, Coventry, Edinburgh (UK), Toronto (Canada), and Sydney (Australia). Congestion charges have been successfully implemented in London, Milan, New York, and Stockholm, for example.
} 
more efficient new cars, and in some cases, more fuel efficient driving patterns (Dhondt et al., 2013; Bjertnæs, 2019).

Second, our study has further implications for policies encouraging active transport. Akin to congestion charges, a straightforward public finance approach could involve a direct subsidy for active modes of travel (Wardman et al., 2007; Regeringskansliet, 2017; EBS, 2020) or indirect subsidies in the form of suitable cycling and washing facilities for employees that would improve comfort of cycling relative to driving (Tilahun et al., 2007).

Appropriate active travel infrastructure may however be a more important "pull" measure to make walking and cycling attractive. ${ }^{32}$ Car-free city centres, bicycle lane networks and improvements in public transport provision will increase the mode share of active travel (Pucher and Buehler, 2007; Buehler and Pucher, 2012; Gössling, 2013), and are actively pursued policies. ${ }^{33}$ For example, in a study of 167 European cities, Mueller et al. (2018) find that increasing bicycle lane infrastructure in urban areas up to $315 \mathrm{~km} / 100,000$ people increases the mode share of cycling up to $24.7 \%$. Further, the lack of appropriate street lighting, and badly maintained roads and cycle lanes have all been identified as factors impeding active commuting (Yang et al., 2017; NHTS, 2019). These policies do not only increase the perceived attractiveness of active travel relative to other modes of transport (Schepers et al., 2015), but also create opportunities to adopt active travel modes to begin with. As such, they have the potential to make the demand for both active miles travelled, and miles by car more responsive to fuel prices. Investing in cycling infrastructure has not been considered a significant investment

\footnotetext{
${ }^{32}$ Standalone marginal increases in fuel taxes are unlikely to spur significant behaviour change in drivers, because the response to a fuel tax is to alter fuel consumption, but not to reduce the amount or distances travelled by car - the demand for VMT is more inelastic than the demand for fuel (Gillingham and Munk-Nielsen, 2019).

${ }^{33}$ For example, Paris is considering developing a 15-minute city plan, where all facilities should be available to every inhabitant within a 15 minute walk (Reid, 2020). Barcelona has begun introducing "superblocks" of $500 \mathrm{~m}^{2}$ that are fully pedestrianised (Mueller et al., 2020). In addition, many cities are focusing on cycling as an alternative to public transport during the COVID-19 pandemic (Sui and Prapavessis, 2020).
} 
strategy until recently, and neither have infrastructure cost assessments been including it in their analyses (Van Essen et al., 2011; Knudsen and Rich, 2013). ${ }^{34}$

Our optimal tax result signals that the extent to which an increase in fuel taxes is welfare enhancing is constrained by the presence of viable low-carbon alternatives (high $\beta$ 's). This result was also demonstrated by Martens (2016), and (in part) justifies the grievances of the Gilets Jaunes movement in France. Conversely, this implies that improvements in infrastructure designed for active travel and public transport as discussed above could further support increased fuel taxation. ${ }^{35}$ While greater willingness of citizens to switch to active travel in particular would manifest itself in a higher responsiveness of active travel to fuel taxation, $\eta^{M^{a c} F}$, it would likely also result in higher active miles travelled $M^{a c}$, lower fuel use $F$, and higher (absolute) elasticities $\eta^{M^{i n} F}$. From (13)-(15), all of these effects would justify higher fuel taxes.

A full characterisation of the "pull effect," would include the public good characteristics of infrastructure - everyone benefits from safer and more comfortable cycling infrastructure - , which will lead individuals to derive more utility from active travel and therefore "pull" them into these modes. This channel is not considered in our model and yet could lead to either higher or lower second-best optimal fuel taxes (Siegmeier, 2016), once infrastructure changes are seen as an additional policy instrument rather than an exogenous change in elasticities (similar to Bovenberg and van der Ploeg, 1994). In other words, as improved public transport infrastructure moves active travel decisions closer to optimal decisions, it may reduce the need for and value of higher fuel taxes as captured through $Z^{Q}$. We believe this is a crucial area for further

\footnotetext{
${ }^{34}$ Health benefits have long been considered the domain of health departments and ministries only, leading to a lack of funding for health improvements in transport and urban planning departments (The European Cyclists' Federation, personal communication).

${ }^{35}$ Future research could investigate how cost-benefit analysis of public transport infrastructure project changes once health benefits are taking into account. Such an analysis should note that the health benefits are unevenly distributed across the population.
} 
work. ${ }^{36}{ }^{37}$

We note a number of limitations to our study: health manifests itself only as an internality within the utility function, though evidence exists to suggest that healthlabour feedback loops, specifically between physical activity and productivity (Van den Heuvel et al., 2005; Proper et al., 2006), and presenteeism (Hemp, 2004; Pereira et al., 2015) do exist. We abstract from these effects in our analysis; if anything, including such effects would strengthen the case for including health benefits from active travel in transport policy assessments. Further, we do not consider distributional concerns of the policy instruments, especially related to income or to race (see Bento et al., 2009, Jephcote et al., 2016, and Tessum et al., 2019). In our context importantly this also means we do not consider heterogeneities in space within a country, although spatial heterogeneity of transport infrastructure matters for the effectiveness of pricing instruments (Creutzig et al., 2020) . We further do not explicitly model pre-existing regulation such as fuel efficiency standards, which are an important element in current transport regulation and limit firms' production possibilities (Greene, 2011). Finally, we combine public transport with walking and cycling as an active mode of transport, and so omit recent trends in urban travel such as ride-hailing and sharing apps such as Uber, or the increasing popularity of e-scooters.

\footnotetext{
${ }^{36}$ Further still, norms, manifestations of (unwritten) rules of a specific culture and information provision can play a relevant role in increasing the effectiveness of fuel taxes and policies aimed at increasing active travel. Cialdini (2003) and Cialdini (2007) suggests using messages with injunctive norms (perceptions about socially- approved behaviours) when the intention is to change an environmentally undesirable but socially-extended behaviour; and using descriptive norms (perceptions about behaviours socially-extended) to reinforce pro-environmental behaviour that is sufficiently present (Nyborg et al., 2016). For further relevance of such norm changes to urban transport, a case of "endogenous preferences or endogenous beliefs," see Mattauch et al. (2016), Mattauch and Hepburn (2016) and Mattauch et al. (2018).

${ }^{37}$ Evidence suggests that the salience of a tax or price change matters and is determined, in part, by its messaging (Dudley, 2013; Uskul and Oyserman, 2010). In the case of fuel taxes (Li et al., 2014) and climate policy (Hirte and Tscharaktschiew, 2015), messaging may increase sensitivity to a price change by up to $70 \%$.
} 


\section{Conclusion}

This article shows that optimal fuel tax rates increase significantly if the health benefits from increased active travel, such as reduced rates of diabetes, cardiovascular diseases, dementia, and depression are not fully internalised by citizens. Building on the established model of optimal fuel taxation developed by Parry and Small (2005), we present an assessment of optimal fuel taxation when an internality through physical inactivity is also considered in the tax design.

We confirm the main conclusion of a large body of research in public health that, per mile travelled, the social costs of inactivity dominate the social costs from transport externalities by two orders of magnitude. We examine how this fact changes the appropriate second-best optimal fuel tax, which targets active travel health benefits only indirectly. We conclude that the second-best optimal fuel tax increases from $\$ 3.35$ to $\$ 4.54 /$ gallon in the UK and $\$ 6.81$ to $\$ 10.13 /$ gallon in the US. Due to the inelastic demand for vehicle miles travelled and cross-elasticity of active travel, the tax rate increases by less than the value of the per-mile internality.

In contrast to Parry and Small (2005), we find that the fuel tax rate in the United Kingdom is close to the optimal when the health benefits from active travel are accounted for, else it would be too high. We confirm that, even without these benefits, in the United States fuel is significantly undertaxed: it exceeds the current average fuel tax rate across the 50 states, as well as the previous estimate by Parry and Small (2005). In fact, the economic cost of damages to human health (air pollution and accident externalities) have risen significantly; more time is being spent in congestion on US roads, and the value of time has also risen faster than inflation. Further, the social cost of carbon estimates we derived from the literature $\left(\$ 40-400 / \mathrm{tCO}_{2}\right)$ are several times higher than the values Parry and Small used in $2005\left(\$ 6.8 / \mathrm{tCO}_{2}, \$ 0.2-27 / \mathrm{tCO}_{2}\right)$. Whereas pollution linked to $\mathrm{CO}_{2}$ emissions contributed the least to their Pigouvian tax component, it is the third largest component according to our estimates. It has 
the most significant influence on the fuel tax as the cost of carbon damages increases. Climate change and urban transport problems have become worse over the past two decades.

Including the significant health benefits from active travel means that fuel taxes should be increased, as they are an established instrument for addressing all social costs of transport. The modest relevance of a fuel tax on an individual's decision to walk or cycle indicates, however, that the fuel tax may not be the most appropriate policy instrument to encourage active travel. This is further reinforced as the optimal US fuel tax can be deemed politically unrealistic. Instead, more targeted measures to increase the relative price of car travel such as congestion charges, and measures aimed at reducing barriers to other modes of transport such as building better active travel infrastructure, will permit societies to reap the high health benefits. Congestion charging would be effective in both the UK and the US for this purpose (Cramton et al., 2018). The US specifically would benefit from more public transit infrastructure that would result in more active trips as people reach the transit stops by foot or bicycle. The UK, characterised by denser cities, would especially benefit from improved urban infrastructure for walking and cycling. Nonetheless, without an associated change in the price signal in the form of a fuel tax rise or congestion charge, infrastructure investment is unlikely to lead to sufficient changes in travel decisions on its own (Buehler et al., 2017; Pucher et al., 2010). Different policies at multiple levels are needed to realise meaningful change in transport. 


\section{References}

Ackerman, Frank and Stanton, Elizabeth (2012). "Climate risks and carbon prices: Revising the social cost of carbon". In: Economics: The Open-Access, Open-Assessment E-Journal 6, p. 10.

Adler, Matthew, Anthoff, David, Bosetti, Valentina, Garner, Greg, Keller, Klaus, and Treich, Nicolas (2017). "Priority for the worse-off and the social cost of carbon". In: Nature Climate Change 7.6, pp. 443-449.

Allcott, Hunt, Lockwood, Benjamin, and Taubinsky, Dmitry (2019a). "Regressive sin taxes, with an application to the optimal soda tax". Tech. rep. National Bureau of Economic Research.

Allcott, Hunt, Lockwood, Benjamin B, and Taubinsky, Dmitry (2019b). "Should we tax soda? an overview of theory and evidence". In: Journal of Economic Perspectives 33.2.

Allcott, Hunt, Mullainathan, Sendhil, and Taubinsky, Dmitry (2014). "Energy policy with externalities and internalities". In: Journal of Public Economics 112, pp. 72-88.

Allcott, Hunt and Sunstein, Cass R (2015). "Regulating internalities". Tech. rep. National Bureau of Economic Research.

Allcott, Hunt and Wozny, Nathan (2014). "Gasoline prices, fuel economy, and the energy paradox". In: Review of Economics and Statistics 96.5, pp. 779-795.

American Petroleum Institute, API (2020). "State Motor Fuel Taxes Report January 2020". URL: https://www .api.org/ /media/Files/Statistics/State-Motor-Fuel-TaxesReport-January-2020.pdf.

Antón-Sarabia, Arturo and Hernández-Trillo, Fausto (2014). "Optimal gasoline tax in developing, oil-producing countries: The case of Mexico". In: Energy Policy 67, pp. 564-571.

Banister, David (2008). "The sustainable mobility paradigm". In: Transport policy 15.2, pp. $73-80$.

Bargain, Olivier, Orsini, Kristian, and Peichl, Andreas (2011). "Labor supply elasticities in Europe and the US". In:

BBC Consulting, contract (2017). "Economic and Health Benefits of Bicycling and Walking for Colorado". URL:

https://choosecolorado.com/wp-content/uploads/2016/06/Economic-andHealth-Benefits-of-Bicycling-and-Walking-in-Colorado-4.pdf.

BBC Consulting, contract (2018). "Economic and Health Benefits of Bicycling in Northwest Arkansas". URL:

https://8ce82b94a8c4fdc3ea6d-b1d233e3bc3cb10858bea65ff05e18f2.ssl.cf2. rackcdn.com/d0/97/cf26b21948308adae6828624729a/march-2018-nw-arkansasfinal-report-corrected.pdf.

BEIS, Department for (2018). "Green Book supplementary guidance: valuation of energy use and greenhouse gas emissions for appraisal". URL: https://www.gov.uk/government/publications/valuation-of-energy-use-andgreenhouse-gas-emissions-for-appraisal.

Bennett, Gary G, Wolin, Kathleen Y, Puleo, Elaine M, Mâsse, Louise C, and Atienza, Audie A (2009). "Awareness of national physical activity recommendations for 
health promotion among US adults". In: Medicine and science in sports and exercise 41.10, p. 1849.

Bento, Antonio M, Goulder, Lawrence H, Jacobsen, Mark R, and Von Haefen, Roger H (2009). "Distributional and efficiency impacts of increased US gasoline taxes". In: American Economic Review 99.3, pp. 667-99.

Besser, Lilah M and Dannenberg, Andrew L (2005). "Walking to public transit: steps to help meet physical activity recommendations". In: American journal of preventive medicine 29.4, pp. 273-280.

Bhargava, Saurabh and Loewenstein, George (2015). "Behavioral economics and public policy 102: Beyond nudging". In: American Economic Review 105.5, pp. 396-401.

Birchby, David, Stedman, John, Whiting, Sally, and Vedrenne, Michel (2019). "Air Quality damage cost update 2019".

Bjertnæs, Geir HM (2019). "Efficient combination of taxes on fuel and vehicles". In: The Energy Journal 40.The New Era of Energy Transition.

Blanchard, Christopher (2009). "The Impact of Rising Gasoline Prices on US Public Transit Ridership". In: PhD diss., Duke University.

Blincoe, Lawrence, Miller, Ted R, Zaloshnja, Eduard, and Lawrence, Bruce A (2015). "The economic and societal impact of motor vehicle crashes, 2010 (Revised)". Tech. rep.

BLS, US (2019). "CONSUMER EXPENDITURES-2019". U.S. Bureau of Labor Statistics Economics News Release. URL: https://www.bls.gov/news.release/cesan.nr0.htm.

Börjesson, Maria and Eliasson, Jonas (2012). "The value of time and external benefits in bicycle appraisal". In: Transportation Research Part A: Policy and Practice 46.4, pp. 673-683.

Bovenberg, Arij Lans and van der Ploeg, Frederick V. (1994). "Environmental policy, public finance and the labour market in a second-best world". In: Journal of Public Economics 55.3, pp. 349-390.

Brand, Christian, Anable, Jillian, and Tran, Martino (2013). "Accelerating the transformation to a low carbon passenger transport system: The role of car purchase taxes, feebates, road taxes and scrappage incentives in the UK". In: Transportation Research Part A: Policy and Practice 49, pp. 132-148.

Bretschger, Lucas and Grieg, Elise (2020). "Exiting the fossil world: The effects of fuel taxation in the UK". In: CER-ETH Economics Working Paper Series 20/332.

Bronnenberg, Bart J, Dube, Jean-Pierre, Gentzkow, Matthew, and Shapiro, Jesse M (2013). "Do pharmacists buy Bayer? Sophisticated shoppers and the brand premium". In: Kilts Center for Marketing at Chicago Booth-Nielsen Dataset Paper Series, pp. 1-017.

Buehler, Ralph and Pucher, John (2012). "Cycling to work in 90 large American cities: new evidence on the role of bike paths and lanes". In: Transportation 39.2, pp. 409-432.

Buehler, Ralph and Pucher, John (2017). "Trends in walking and cycling safety: recent evidence from high-income countries, with a focus on the United States and Germany". In: American journal of public health 107.2, pp. 281-287.

Buehler, Ralph, Pucher, John, Gerike, Regine, and Götschi, Thomas (2017). "Reducing car dependence in the heart of Europe: lessons from Germany, Austria, and Switzerland". In: Transport reviews 37.1, pp. 4-28.

Cai, Yongyang and Lontzek, Thomas S (2019). "The social cost of carbon with economic and climate risks". In: Journal of Political Economy 127.6, pp. 2684-2734.

Calzolari, Giacomo and Nardotto, Mattia (2017). "Effective reminders". In: Management Science 63.9, pp. 2915-2932. 
Castro, Alberto, Gaupp-Berghausen, Mailin, Dons, Evi, Standaert, Arnout, Laeremans, Michelle, Clark, Anna, Anaya-Boig, Esther, Cole-Hunter, Tom, Avila-Palencia, Ione, Rojas-Rueda, David, et al. (2019). "Physical activity of electric bicycle users compared to conventional bicycle users and non-cyclists: Insights based on health and transport data from an online survey in seven European cities". In: Transportation research interdisciplinary perspectives 1, p. 100017.

Catalan-Matamoros, Daniel, Gomez-Conesa, Antonia, Stubbs, Brendon, and Vancampfort, Davy (2016). "Exercise improves depressive symptoms in older adults: an umbrella review of systematic reviews and meta-analyses". In: Psychiatry research 244, pp. 202-209.

Cerruti, Davide, Alberini, Anna, and Linn, Joshua (2019). "Charging Drivers by the Pound: How Does the UK Vehicle Tax System Affect CO 2 Emissions?" In: Environmental and Resource Economics, pp. 1-31.

Chalom, André and de Prado, Paulo Inácio de Knegt López (2015). "Uncertainty analysis and composite hypothesis under the likelihood paradigm". In: arXiv preprint arXiv:1508.03354.

Charness, Gary and Gneezy, Uri (2009). "Incentives to exercise". In: Econometrica 77.3, pp. 909-931.

Chetty, Raj (2015). "Behavioral economics and public policy: A pragmatic perspective". In: American Economic Review 105.5, pp. 1-33.

Cialdini, Robert B (2003). "Crafting normative messages to protect the environment". In: Current directions in psychological science 12.4, pp. 105-109.

Cialdini, Robert B (2007). "Descriptive social norms as underappreciated sources of social control". In: Psychometrika 72.2, p. 263.

Coglianese, John, Davis, Lucas W, Kilian, Lutz, and Stock, James H (2017). "Anticipation, tax avoidance, and the price elasticity of gasoline demand". In: Journal of Applied Econometrics 32.1, pp. 1-15.

Cookson, Graham (2016). "Europes Traffic Hotspots Measuring the impact of congestion". In: INRIX Research. URL: http://www2.inrix.com/traffic-hotspots-research2016?utm_medium=referral\&utm_source=inrix\&utm_campaign=roadwayanalytics\&utm_term=research-report\&utm_content=press-release.

Cramton, Peter, Geddes, R Richard, and Ockenfels, Axel (2018). "Set road charges in real time to ease traffic".

Creutzig, Felix and He, Dongquan (2009). "Climate change mitigation and co-benefits of feasible transport demand policies in Beijing". In: Transportation Research Part D: Transport and Environment 14.2, pp. 120-131.

Creutzig, Felix, Javaid, Aneeque, Koch, Nicolas, Knopf, Brigitte, Mattioli, Giulio, and Edenhofer, Ottmar (2020). "Adjust urban and rural road pricing for fair mobility". In: Nature Climate Change, pp. 1-4.

Crisp, Roger (2017). "Well-Being". In: The Stanford Encyclopedia of Philosophy. Ed. by Edward N. Zalta. Fall 2017. Metaphysics Research Lab, Stanford University.

Currie, Graham and Phung, Justin (2007). "Transit ridership, auto gas prices, and world events: new drivers of change?" In: Transportation Research Record 1992.1, pp. 3-10.

Currie, Graham and Phung, Justin (2008). "Understanding links between transit ridership and gasoline prices: evidence from the United States and Australia". In: Transportation Research Record 2063.1, pp. 133-142. 
Dahl, Carol A (2012). "Measuring global gasoline and diesel price and income elasticities". In: Energy Policy 41, pp. 2-13.

Davies, Sally C, Atherton, Frank, McBride, Michael, and Calderwood, Catherine (2019). "UK Chief Medical Officers' physical activity guidelines 2019".

Davis, Lucas W and Kilian, Lutz (2011). "Estimating the effect of a gasoline tax on carbon emissions". In: Journal of Applied Econometrics 26.7, pp. 1187-1214.

De Nazelle, Audrey, Bode, Olivier, and Orjuela, Juan Pablo (2017). "Comparison of air pollution exposures in active vs. passive travel modes in European cities: a quantitative review". In: Environment international 99, pp. 151-160.

De Borger, Bruno, Mulalic, Ismir, and Rouwendal, Jan (2016). "Substitution between cars within the household". In: Transportation Research Part A: Policy and Practice 85, pp. $135-156$.

De Hartog, Jeroen Johan, Boogaard, Hanna, Nijland, Hans, and Hoek, Gerard (2010). "Do the health benefits of cycling outweigh the risks?" In: Environmental health perspectives 118.8, pp. 1109-1116.

De Souza, Adriana A, Sanches, Suely P, and Ferreira, Marcos AG (2014). "Influence of attitudes with respect to cycling on the perception of existing barriers for using this mode of transport for commuting". In: Procedia-Social and Behavioral Sciences 162, pp. 111-120.

Deenihan, Gerard and Caulfield, Brian (2014). "Estimating the health economic benefits of cycling". In: Journal of Transport \& Health 1.2, pp. 141-149.

DellaVigna, Stefano (2009). "Psychology and economics: Evidence from the field". In: Journal of Economic literature 47.2, pp. 315-72.

DellaVigna, Stefano and Malmendier, Ulrike (2006). "Paying not to go to the gym". In: american economic Review 96.3, pp. 694-719.

DfT, Department for Transport (2018a). "Accident and casualty costs (RAS60)". URL: https://www .gov.uk/government/statistical-data-sets/ras60-average-valueof-preventing-road-accidents.

DfT, Department for Transport (2018b). "Energy and environment: data tables (ENV)". URL: https://www.gov.uk/government/statistical-data-sets/energy-andenvironment-data-tables-env\#fuel-consumption-env01.

DfT, Department for Transport (2018c). "Road traffic statistics (TRA)". URL: https: //www.gov.uk/government/statistical-data-sets/road-traffic-statistics-tra.

Dhondt, Stijn, Kochan, Bruno, Beckx, Carolien, Lefebvre, Wouter, Pirdavani, Ali, Degraeuwe, Bart, Bellemans, Tom, Panis, Luc Int, Macharis, Cathy, and Putman, Koen (2013). "Integrated health impact assessment of travel behaviour: model exploration and application to a fuel price increase". In: Environment international 51, pp. 45-58.

Dieler, Julian, Jus, Darko, and Zimmer, Markus (2015). "Fill'er up-The effect of fuel taxes on carbon emissions". In: Manuscript, CESifo, Munich.

Dons, Evi, Rojas-Rueda, David, Anaya-Boig, Esther, Avila-Palencia, Ione, Brand, Christian, Cole-Hunter, Tom, de Nazelle, Audrey, Eriksson, Ulf, Gaupp-Berghausen, Mailin, Gerike, Regine, et al. (2018). "Transport mode choice and body mass index: cross-sectional and longitudinal evidence from a European-wide study". In: Environment international 119, pp. 109-116.

Dudley, Geoff (2013). "Why do ideas succeed and fail over time? The role of narratives in policy windows and the case of the London congestion charge". In: Journal of European Public Policy 20.8, pp. 1139-1156. 
EBS, Employee Benefits Scheme (2020). "The UK's Most Popular Cycle to Work Benefit Cyclescheme". URL: https://www.cyclescheme.co.uk/.

Ellis, David and Glover, Brianne (2019). "2019 URBAN MOBILITY REPORT". In:

Elvik, Rune and Bjørnskau, Torkel (2017). "Safety-in-numbers: a systematic review and meta-analysis of evidence". In: Safety science 92, pp. 274-282.

Environmental Protection Agency, USA (2016). "Technical Support Document:-Technical Update of the Social Cost of Carbon for Regulatory Impact Analysis-Under Executive Order 12866". In: Domestic Policy Council.

EPA (2017). "Particulate Matter (PM2.5) Trends". United States Environmental Protection Agency. URL: https://www.epa.gov/air-trends/particulate-matter-pm25-trends.

Erosa, Andrés, Fuster, Luisa, and Kambourov, Gueorgui (2016). "Towards a micro-founded theory of aggregate labour supply". In: The Review of Economic Studies 83.3, pp. 1001-1039.

Eurobarometer, Special (2018). "472.(2018)". In: Sport and physical activity: report. Bruselj: European Commission. Dostupno 28.2.

Federal Highway Administration, 2018 Statistics (2018). "Annual Vehicle Distance Traveled in Miles and Related Data - 2016 (1) by Highway Category and Vehicle Type". URL: https://www.fhwa.dot.gov/policyinformation/statistics/2016/vm1.cfm.

Fishman, Elliot, Schepers, Paul, and Kamphuis, Carlijn Barbara Maria (2015). "Dutch cycling: quantifying the health and related economic benefits". In: American journal of public health 105.8, e13-e15.

Fleurbaey, Marc and Blanchet, Didier (2013). "Beyond GDP: Measuring welfare and assessing sustainability". Oxford University Press.

Foley, Louise, Panter, Jenna, Heinen, Eva, Prins, Richard, and Ogilvie, David (2015). "Changes in active commuting and changes in physical activity in adults: a cohort study". In: International Journal of Behavioral Nutrition and Physical Activity 12.1, p. 161.

Fouquet, Roger (2012). "Trends in income and price elasticities of transport demand (1850-2010)". In: Energy Policy 50, pp. 62-71.

Fredriksson, Sara Veronica, Alley, Stephanie J, Rebar, Amanda L, Hayman, Melanie, Vandelanotte, Corneel, and Schoeppe, Stephanie (2018). "How are different levels of knowledge about physical activity associated with physical activity behaviour in Australian adults?" In: PLoS One 13.11, e0207003.

Frondel, Manuel and Vance, Colin (2013). "Re-identifying the rebound: what about asymmetry?" In: The Energy Journal, pp. 43-54.

$\mathrm{Fu}$, Liwei and Farber, Steven (2017). "Bicycling frequency: A study of preferences and travel behavior in Salt Lake City, Utah". In: Transportation research part A: policy and practice 101, pp. 30-50.

Gabbatiss, Josh (2018). "Transport is UK's most polluting sector as greenhouse gas emissions fall". URL: https://www.independent.co.uk/environment/air-pollutionuk-transport-most-polluting-sector-greenhouse-gas-emissions-drop-carbondioxide-a8196866.html.

Gibson-Moore, H (2019). "UK Chief Medical Officers' physical activity guidelines 2019: What's new and how can we get people more active?" In: Nutrition Bulletin 44.4, pp. $320-328$.

Gillingham, Kenneth and Munk-Nielsen, Anders (2019). "A tale of two tails: Commuting and the fuel price response in driving". In: Journal of Urban Economics 109, pp. 27-40. 
Gössling, Stefan (2013). "Urban transport transitions: Copenhagen, city of cyclists". In: Journal of Transport Geography 33, pp. 196-206.

Graham, Daniel J and Glaister, Stephen (2002). "The demand for automobile fuel: a survey of elasticities". In: Journal of Transport Economics and policy, pp. 1-25.

Greene, David L (2011). "Uncertainty, loss aversion, and markets for energy efficiency". In: Energy Economics 33.4, pp. 608-616.

Grigoratos, Theodoros and Martini, Giorgio (2014). "Non-exhaust traffic related emissions. Brake and tyre wear PM: Literature Review". URL: https:

//publications.jrc.ec.europa.eu/repository/bitstream/JRC89231/jrc89231online $\ \% 20$ final $\backslash \% 20$ version $\backslash \% 202$.pdf.

Gruber, Jonathan and Kőszegi, Botond (2004). "Tax incidence when individuals are time-inconsistent: the case of cigarette excise taxes". In: Journal of Public Economics 88.9-10, pp. 1959-1987.

Guo, Qianwen, Sun, Yanshuo, Li, Zhi-Chun, and Li, Zhongfei (2017). "An integrated model for road capacity choice and cordon toll pricing". In: Research in Transportation Economics 62, pp. 68-79.

Hague Publishing, Group, ARPA, Bosenfeld, Heusch, Stratec, and de Cergy-Pontoise, Université (1999). "TRACE Final Report for Publication". European Commission Contract RO-97-SC.2035. URL: https : //trimis.ec.europa.eu/sites/default/files/project/documents/trace.pdf.

Haire, Ashley R and Machemehl, Randy B (2007). "Impact of rising fuel prices on US transit ridership". In: Transportation Research Record 1992.1, pp. 11-19.

Handel, Benjamin R and Kolstad, Jonathan T (2015). "Health insurance for" humans": Information frictions, plan choice, and consumer welfare". In: American Economic Review 105.8, pp. 2449-2500.

Hänsel, Martin C, Drupp, Moritz A, Johansson, Daniel JA, Nesje, Frikk, Azar, Christian, Freeman, Mark C, Groom, Ben, and Sterner, Thomas (2020). "Climate economics support for the UN climate targets". In: Nature Climate Change, pp. 1-9.

Havranek, Tomas, Irsova, Zuzana, and Janda, Karel (2012). "Demand for gasoline is more price-inelastic than commonly thought". In: Energy Economics 34.1, pp. 201-207.

Hemp, Paul (2004). "Presenteeism: at work-but out of it". In: Harvard business review 82.10, pp. $49-58$.

Hensher, David A and King, Jenny (1998). "Establishing fare elasticity regimes for urban passenger transport: Time-based fares for concession and non-concession markets segmented by trip length". In: Journal of Transportation and Statistics 1.1, pp. 43-61.

Hirte, Georg and Tscharaktschiew, Stefan (2015). "Optimal fuel taxes and heterogeneity of cities". In: Review of Regional Research 35.2, pp. 173-209.

Hitchcock, G, Conlan, B, Kay, D, Brannigan, C, and Newman, D (2014). "Air quality and road transport: Impacts and solutions". In:

Hockstad, Leif and Hanel, L (2018). "Inventory of US greenhouse gas emissions and sinks". Tech. rep. Environmental System Science Data Infrastructure for a Virtual Ecosystem.

Holmgren, Johan (2007). "Meta-analysis of public transport demand". In: Transportation Research Part A: Policy and Practice 41.10, pp. 1021-1035.

Hughes, Jonathan E, Knittel, Christopher R, and Sperling, Daniel (2006). "Evidence of a shift in the short-run price elasticity of gasoline demand". Tech. rep. National Bureau of Economic Research.

Inrix (2018). "Inrix Congestion Scorecard 2018". URL: http://inrix.com/scorecard/. 
Inrix (2019). "Press release: Congestion Costs U.K. Nearly £8 Billion in 2018". URL: http://inrix.com/press-releases/scorecard-2018-uk/.

Iseki, Hiroyuki, Ali, Rubaba, et al. (2014). "Net effects of gasoline price changes on transit ridership in US urban areas." Tech. rep. Mineta Transportation Institute.

James, Peter, Ito, Kate, Buonocore, Jonathan, Levy, Jonathan, and Arcaya, Mariana (2014). "A health impact assessment of proposed public transportation service cuts and fare increases in Boston, Massachusetts (USA)". In: International journal of environmental research and public health 11.8, pp. 8010-8024.

Jephcote, Calvin, Chen, Haibo, and Ropkins, Karl (2016). "Implementation of the Polluter-Pays Principle (PPP) in local transport policy". In: Journal of Transport Geography 55, pp. 58-71.

Johansson, Olof and Schipper, Lee (1997). "Measuring the long-run fuel demand of cars: separate estimations of vehicle stock, mean fuel intensity, and mean annual driving distance". In: Journal of Transport Economics and policy, pp. 277-292.

Kahlmeier, Sonja, Götschi, Thomas, Cavill, Nick, Castro Fernandez, Alberto, Brand, Christian, Rojas Rueda, David, Woodcock, James, Kelly, Paul, Lieb, Christoph, Oja, Pekka, et al. (2017). "Health economic assessment tool (HEAT) for walking and for cycling. Methods and user guide on physical activity, air pollution, injuries and carbon impact assessments". In:

Klenert, David, Mattauch, Linus, Combet, Emmanuel, Edenhofer, Ottmar, Hepburn, Cameron, Rafaty, Ryan, and Stern, Nicholas (2018). "Making carbon pricing work for citizens". In: Nature Climate Change 8.8, pp. 669-677.

Knittel, Christopher R and Sandler, Ryan (2013). "The welfare impact of indirect pigouvian taxation: Evidence from transportation". Tech. rep. National Bureau of Economic Research.

Knudsen, M Aa and Rich, Jeppe (2013). "Ex post socio-economic assessment of the Oresund Bridge". In: Transport policy 27, pp. 53-65.

Laeremans, Michelle, Gotschi, Thomas, Dons, Evi, Kahlmeier, Sonja, Brand, Christian, de Nazelle, Audrey, Gerike, Regine, Nieuwenhuijsen, Mark, Raser, Elisabeth, Stigell, Erik, et al. (2017). "Does an Increase in Walking and Cycling Translate into a Higher Overall Physical Activity Level?" In: Journal of Transport 83 Health 5, S20.

Laibson, David (1997). "Golden eggs and hyperbolic discounting". In: The Quarterly Journal of Economics 112.2, pp. 443-478.

Lane, Bradley W (2008). "Gasoline Costs, Public Transit, And Sustainability". In: Peer Reviewed Conference Paper, Berkeley Electronic Press (http://works ...

Lee, Jaimin, Han, Sangyong, and Lee, Chang-Woon (2009). "Oil price and travel demand". In: pp. $1-88$.

Lemp, Jason D and Kockelman, Kara M (2008). "Quantifying the external costs of vehicle use: Evidence from America's top-selling light-duty models". In: Transportation research part D: transport and environment 13.8, pp. 491-504.

Lepoutre, Manoelle (2018). "Greenhouse Gas Emissions in France". URL: https://www.planete-energies.com/en/medias/close/greenhouse-gasemissions-france.

Levin, Laurence, Lewis, Matthew S, and Wolak, Frank A (2017). "High frequency evidence on the demand for gasoline". In: American Economic Journal: Economic Policy 9.3, pp. $314-47$. 
Li, Shanjun, Linn, Joshua, and Muehlegger, Erich (2014). "Gasoline taxes and consumer behavior". In: American Economic Journal: Economic Policy 6.4, pp. 302-42.

Li, Yanping, Schoufour, Josje, Wang, Dong D, Dhana, Klodian, Pan, An, Liu, Xiaoran, Song, Mingyang, Liu, Gang, Shin, Hyun Joon, Sun, Qi, Al-Shaar, Laila, Wang, Molin, Rimm, Eric B, Hertzmark, Ellen, Stampfer, Meir J, Willett, Walter C, Franco, Oscar H, and $\mathrm{Hu}$, Frank B (2020). "Healthy lifestyle and life expectancy free of cancer, cardiovascular disease, and type 2 diabetes: prospective cohort study". In: BMJ 368 . DOI: $10.1136 / \mathrm{bmj} .16669$. eprint: https://www.bmj.com/content/368/bmj .16669.full.pdf. URL: https: //www.bmj. com/content/368/bmj . 16669.

Litman, Todd (2013). "Transport Elasticities: Impacts on Travel Behaviour". Tech. rep. Litman, Todd (2019). "Transit Price Elasticities and Cross-Elasticities". In:

Liu, Xuejiao, Zhang, Dongdong, Liu, Yu, Sun, Xizhuo, Han, Chengyi, Wang, Bingyuan, Ren, Yongcheng, Zhou, Junmei, Zhao, Yang, Shi, Yuanyuan, et al. (2017).

"Dose-response association between physical activity and incident hypertension: a systematic review and meta-analysis of cohort studies". In: Hypertension 69.5, pp. 813-820.

Loprinzi, Paul D, Edwards, Meghan K, Crush, Elizabeth, Ikuta, Toshikazu, and Del Arco, Alberto (2018). "Dose-response association between physical activity and cognitive function in a national sample of older adults". In: American Journal of Health Promotion 32.3, pp. 554-560.

Maghelal, Praveen (2011). "Investigating the relationships among rising fuel prices, increased transit ridership, and CO2 emissions". In: Transportation Research Part D: Transport and Environment 16.3, pp. 232-235.

Maizlish, Neil, Linesch, Nicholas J, and Woodcock, James (2017). "Health and greenhouse gas mitigation benefits of ambitious expansion of cycling, walking, and transit in California". In: Journal of transport \& health 6, pp. 490-500.

Maley, Donald W and Weinberger, Rachel (2009). "Rising gas price and transit ridership: case study of Philadelphia, Pennsylvania". In: Transportation research record 2139.1, pp. $183-188$.

Martens, Karel (2016). "Transport justice: Designing fair transportation systems". Routledge.

Martin, Adam, Suhrcke, Marc, and Ogilvie, David (2012). "Financial incentives to promote active travel: an evidence review and economic framework". In: American journal of preventive medicine 43.6, e45-e57.

Mashayekh, Yeganeh, Jaramillo, Paulina, Chester, Mikhail, Hendrickson, Chris T, and Weber, Christopher L (2011). "Costs of automobile air emissions in US metropolitan areas". In: Transportation Research Record 2233.1, pp. 120-127.

Mattauch, Linus and Hepburn, Cameron (2016). "Climate policy when preferences are endogenous - and sometimes they are". In: Midwest Studies In Philosophy 1.

Mattauch, Linus, Hepburn, Cameron, and Stern, Nicholas (2018). "Pigou pushes preferences: decarbonisation and endogenous values". In:

Mattauch, Linus, Ridgway, Monica, and Creutzig, Felix (2016). "Happy or liberal? Making sense of behavior in transport policy design". In: Transportation research part D: transport and environment 45, pp. 64-83. 
Mattioli, Giulio, Wadud, Zia, and Lucas, Karen (2018). "Vulnerability to fuel price increases in the UK: A household level analysis". In: Transportation Research Part A: Policy and Practice 113, pp. 227-242.

Mattson, Jeremy Wade (2008). "Effects of rising gas prices on bus ridership for small urban and rural transit systems". Upper Great Plains Transportation Institute, North Dakota State University Fargo.

Moran, Molly and Monje, Carlos (2016). "Revised Departmental Guidance on Valuation of a Statistical Life in Economic Analysis". URL:

https://www . transportation.gov/office-policy/transportationpolicy/revised-departmental-guidance-on-valuation-of-a-statistical-lifein-economic-analysis.

Mueller, Natalie, Rojas-Rueda, David, Cole-Hunter, Tom, De Nazelle, Audrey, Dons, Evi, Gerike, Regine, Goetschi, Thomas, Panis, Luc Int, Kahlmeier, Sonja, and Nieuwenhuijsen, Mark (2015). "Health impact assessment of active transportation: a systematic review". In: Preventive medicine 76, pp. 103-114.

Mueller, Natalie, Rojas-Rueda, David, Khreis, Haneen, Cirach, Marta, Andrés, David, Ballester, Joan, Bartoll, Xavier, Daher, Carolyn, Deluca, Anna, Echave, Cynthia, et al. (2019). "Changing the urban design of cities for health: the superblock model". In: Environment international, p. 105132.

Mueller, Natalie, Rojas-Rueda, David, Khreis, Haneen, Cirach, Marta, Andrés, David, Ballester, Joan, Bartoll, Xavier, Daher, Carolyn, Deluca, Anna, Echave, Cynthia, et al. (2020). "Changing the urban design of cities for health: the Superblock model". In: Environment international 134, p. 105132.

Mueller, Natalie, Rojas-Rueda, David, Salmon, Maëlle, Martinez, David, Ambros, Albert, Brand, Christian, de Nazelle, Audrey, Dons, Evi, Gaupp-Berghausen, Mailin, Gerike, Regine, et al. (2018). "Health impact assessment of cycling network expansions in European cities". In: Preventive medicine 109, pp. 62-70.

Muller, Nicholas Z, Mendelsohn, Robert, and Nordhaus, William (2011). "Environmental accounting for pollution in the United States economy". In: American Economic Review 101.5, pp. 1649-75.

Murphy, Sherry L, Xu, JQ, Kochanek, Kenneth D, and Arias, E (2018). "Mortality in the United States, 2017. NCHS data brief, No 328". In: Hyattsville, MD: National Center for Health Statistics.

Newbery, David M et al. (1995). "Royal Commission Report on Transport and the Environment-Economic Effects of Recommendations". In: Economic Journal 105.432, pp. $1258-1272$.

NHTS, US (2019). "Changing Attitudes and Transportation Choices: 2017 National Household Travel Survey". URL: https://nhts.ornl.gov/assets/FHWA_NHTS_Report_3E_Final_021119.pdf.

Nieuwenhuijsen, Mark and Khreis, Haneen (2018). "Integrating human health into urban and transport planning". In: Cham, Switzerland: Springer.

Nordhaus, William (2018). "Evolution of modeling of the economics of global warming: Changes in the DICE model, 1992-2017". In: Climatic change 148.4, pp. 623-640.

Nyborg, Karine, Anderies, John M, Dannenberg, Astrid, Lindahl, Therese, Schill, Caroline, Schlüter, Maja, Adger, W Neil, Arrow, Kenneth J, Barrett, Scott, Carpenter, Stephen, et al. (2016). "Social norms as solutions". In: Science 354.6308, pp. 42-43. 
O’Donoghue, Ted and Rabin, Matthew (1999). "Doing it now or later". In: American economic review 89.1, pp. 103-124.

O’Donoghue, Ted and Rabin, Matthew (2006). "Optimal sin taxes". In: Journal of Public Economics 90.10-11, pp. 1825-1849.

OECD (2015). "Cost of Air Pollution Policy Highlights". URL: https://issuu.com/oecd.publishing/docs/highlights_cost_of_air_pollution_ $\mathrm{pr} / 4$ ?ff\&e $=3055080 / 12038194$.

OECD (2019). "Taxing Energy Use 2019", p. 105. DOI: https://doi.org/https://doi.org/10.1787/058ca239-en. URL: https://www. oecd-ilibrary.org/content/publication/058ca239-en.

OECD, Organisation (2012). "Mortality risk valuation in environment, health and transport policies". OECD Publishing.

OECD, Organisation (2018). "Cost benefit analysis and the environment". URL: https://read.oecd-ilibrary.org/environment/cost-benefit-analysis-and-theenvironment/the-social-cost-of-carbon_9789264085169-17-en\#page1.

Onambele-Pearson, Gladys, Wullems, Jorgen, Doody, Conor, Ryan, Declan, Morse, Christopher, and Degens, Hans (2019). "Influence of Habitual Physical Behavior-Sleeping, Sedentarism, Physical Activity-On Bone Health in Community-Dwelling Older People". In: Frontiers in physiology 10.

ONS (2019). "Average weekly household expenditure on fuel by gross income decile group, UK, financial year ending 2018". Office for National Statistics ref 009534. URL: https://www.ons.gov.uk/peoplepopulationandcommunity/ personalandhouseholdfinances/expenditure/adhocs/ 009534averageweeklyhouseholdexpenditureonfuelbygrossincomedecilegroupukf inancialyearendin

OSG, US (2015). "Step it up! The surgeon general's call to action to promote walking and walkable communities". Washington, DC: US Dept of Health and Human Services, Office of the Surgeon General. URL: http: //www.surgeongeneral.gov/library/calls/walking-and-walkable-communities.

Parry, Ian WH, Heine, Mr Dirk, Lis, Eliza, and Li, Shanjun (2014). "Getting energy prices right: From principle to practice". International Monetary Fund.

Parry, Ian WH and Small, Kenneth A (2004). "Does Britain or the United States have the right gasoline tax?" Resources for the Future, first published March 2002, rev. Sept. 2004.

Parry, Ian WH and Small, Kenneth A (2005). "Does Britain or the United States have the right gasoline tax?" In: American Economic Review 95.4, pp. 1276-1289.

Parry, Ian WH, Walls, Margaret, and Harrington, Winston (2007). "Automobile externalities and policies". In: Journal of economic literature 45.2, pp. 373-399.

Patel, Vasita (2017). "Deaths registered in England and Wales: 2016". In: Office for National Statistics.

Pereira, Michelle Jessica, Coombes, Brooke Kaye, Comans, Tracy Anne, and Johnston, Venerina (2015). "The impact of onsite workplace health-enhancing physical activity interventions on worker productivity: a systematic review". In: Occup Environ Med 72.6, pp. 401-412.

Pindyck, Robert S (2019). "The social cost of carbon revisited". In: Journal of Environmental Economics and Management 94, pp. 140-160. 
Proper, Karin I, Van den Heuvel, SG, De Vroome, EM, Hildebrandt, VH, and Van der Beek, AJ (2006). "Dose-response relation between physical activity and sick leave". In: British journal of sports medicine 40.2, pp. 173-178.

Pucher, John and Buehler, Ralph (2007). "At the frontiers of cycling: policy innovations in the Netherlands, Denmark, and Germany". In: World Transport Policy and Practice 13.3 , pp. 8-57.

Pucher, John, Dill, Jennifer, and Handy, Susan (2010). "Infrastructure, programs, and policies to increase bicycling: an international review". In: Preventive medicine 50, S106-S125.

Rabl, Ari and De Nazelle, Audrey (2012). "Benefits of shift from car to active transport". In: Transport policy 19.1, pp. 121-131.

RAC, Foundation (2020). URL: https://www.racfoundation.org/data/uk-daily-fuel-table-with-breakdown.

Regeringskansliet (2017). "Tydlig miljöprofil i budgeten för år 2018". URL: https://www.regeringen. se/artiklar/2017/09/tydlig-miljoprofil-i-budgetenfor-ar-2018/.

Reid, Carlton (2019). "Most Cities Will Have To Introduce Congestion Charging, Say Experts At Global Transit Conference". URL: https://www.forbes.com/sites/carltonreid/2019/06/10/most-cities-willhave-to-introduce-congestion-charging-say-experts-at-global-transitconference/\#3221ae95536f.

Reid, Carlton (2020). "Phasing Out Cars Key To Paris Mayor's Plans For 15-Minute City". URL: https://www . forbes.com/sites/carltonreid/2020/01/21/phasing-out-carskey-to-paris-mayors-plans-for-15-minute-city/\#641bcd066952.

Reis, Rodrigo S, Salvo, Deborah, Ogilvie, David, Lambert, Estelle V, Goenka, Shifalika, Brownson, Ross C, Committee, Lancet Physical Activity Series 2 Executive, et al. (2016). "Scaling up physical activity interventions worldwide: stepping up to larger and smarter approaches to get people moving". In: The lancet 388.10051, pp. 1337-1348.

Ricke, Katharine, Drouet, Laurent, Caldeira, Ken, and Tavoni, Massimo (2018). "Country-level social cost of carbon". In: Nature Climate Change 8.10, p. 895.

Rietveld, Piet and van Woudenberg, Stefan (2005). "Why fuel prices differ". In: Energy Economics 27.1, pp. 79-92.

Rissel, Chris, Curac, Nada, Greenaway, Mark, and Bauman, Adrian (2012). "Physical activity associated with public transport use - a review and modelling of potential benefits". In: International journal of environmental research and public health 9.7, pp. 2454-2478.

San Diego, Emily Rose N and Merz, Erin L (2020). "Diabetes knowledge, fatalism and type 2 diabetes-preventive behavior in an ethnically diverse sample of college students". In: Journal of American College Health, pp. 1-10.

Sansom, Tom, Nash, Chris, Mackie, Peter, Shires, Jeremy, and Watkiss, P (2001). "Surface transport costs and charges". In: Institute for Transport Studies, University of Leeds.

Santos, Georgina (2017). "Road fuel taxes in Europe: Do they internalize road transport externalities?" In: Transport Policy 53, pp. 120-134.

Santos, Georgina and Catchesides, Tom (2005). "Distributional consequences of gasoline taxation in the United Kingdom". In: Transportation Research Record 1924.1, pp. 103-111. 
Schepers, Paul, Fishman, Elliot, Beelen, Rob, Heinen, Eva, Wijnen, Wim, and Parkin, John (2015). "The mortality impact of bicycle paths and lanes related to physical activity, air pollution exposure and road safety". In: Journal of Transport \& Health 2.4, pp. 460-473.

Shipman, Matt (2019). "Shared E-Scooters Aren't Always as Green as Other Transport Options". URL: https://news.ncsu.edu/2019/08/impact-of-e-scooters/.

Shogren, Jason F and Taylor, Laura O (2008). "On behavioral-environmental economics". In: Review of Environmental Economics and Policy 2.1, pp. 26-44.

Siegmeier, Jan (2016). "Keeping Pigou on tracks: second-best combinations of carbon pricing and infrastructure provision". In: Work. Pap 2.2016, pp. 17-02.

Small, Kenneth A, Van Dender, Kurt, et al. (2007). "Fuel efficiency and motor vehicle travel: the declining rebound effect". In: ENERGY JOURNAL-CAMBRIDGE MA THEN CLEVELAND OH-28.1, p. 25.

Smith, Andrea D, Crippa, Alessio, Woodcock, James, and Brage, Søren (2016). "Physical activity and incident type 2 diabetes mellitus: a systematic review and dose-response meta-analysis of prospective cohort studies".

Steinhilber, Brianna (2017). "Why walking is the most underrated form of exercise". URL: https://www .nbcnews. com/better/health/why-walking-most-underrated-formexercise-ncna797271.

Sterner, Thomas (2012). "Distributional effects of taxing transport fuel". In: Energy Policy 41 , pp. $75-83$.

Sui, Wuyou and Prapavessis, Harry (2020). "COVID-19 has created more cyclists: How cities can keep them on their bikes". URL: https://phys .org/news/2020-06-covid-cyclists-cities-bikes.html.

Tainio, Marko, de Nazelle, Audrey J, Götschi, Thomas, Kahlmeier, Sonja, Rojas-Rueda, David, Nieuwenhuijsen, Mark J, de Sá, Thiago Hérick, Kelly, Paul, and Woodcock, James (2016). "Can air pollution negate the health benefits of cycling and walking?" In: Preventive Medicine 87, pp. 233-236.

Tessum, Christopher W, Apte, Joshua S, Goodkind, Andrew L, Muller, Nicholas Z, Mullins, Kimberley A, Paolella, David A, Polasky, Stephen, Springer, Nathaniel P, Thakrar, Sumil K, Marshall, Julian D, et al. (2019). "Inequity in consumption of goods and services adds to racial-ethnic disparities in air pollution exposure". In: Proceedings of the National Academy of Sciences 116.13, pp. 6001-6006.

Thomas, Philip (2020). "Minimum sample size for the survey measurement of a wealth-dependent parameter with the UK VPF as exemplar". In: Measurement 150, p. 107044.

Tilahun, Nebiyou Y, Levinson, David M, and Krizek, Kevin J (2007). "Trails, lanes, or traffic: Valuing bicycle facilities with an adaptive stated preference survey". In: Transportation Research Part A: Policy and Practice 41.4, pp. 287-301.

Tol, Richard SJ (2011). "The social cost of carbon". In: Annu. Rev. Resour. Econ. 3.1, pp. 419-443.

Useche, Sergio A, Montoro, Luis, Sanmartin, Jaime, and Alonso, Francisco (2019). "Healthy but risky: A descriptive study on cyclists' encouraging and discouraging factors for using bicycles, habits and safety outcomes". In: Transportation research part F: traffic psychology and behaviour 62, pp. 587-598.

Uskul, Ayse K and Oyserman, Daphna (2010). "When message-frame fits salient cultural-frame, messages feel more persuasive". In: Psychology and Health 25.3, pp. 321-337. 
Van Essen, Huib, van Wijngaarden, Lisanne, Schroten, Arno, Sutter, Daniel, Bieler, Cuno, Maffii, Silvia, Brambilla, Marco, Fiorello, Davide, Fermi, Francesca, Parolin, Riccardo, et al. (2019). "Handbook on the External Costs of Transport, Version 2019". Tech. rep.

Van den Bijgaart, Inge, Gerlagh, Reyer, and Liski, Matti (2016). "A simple formula for the social cost of carbon". In: Journal of Environmental Economics and Management 77, pp. $75-94$.

Van den Heuvel, SG, Boshuizen, HC, Hildebrandt, VH, Blatter, BM, Ariëns, GA, and Bongers, PM (2005). "Effect of sporting activity on absenteeism in a working population". In: British journal of sports medicine 39.3, e15-e15.

Van Essen, Huib, Schroten, Arno, Otten, Matthijs, Sutter, Daniel, Schreyer, Christoph, Zandonella, Remo, Maibach, Markus, and Doll, Claus (2011). "External Costs of Transport in Europe, Update Study for 2008". In: Delft, CE Delft, Publication code 11.50, p. 161.

Wardman, Mark, Tight, Miles, and Page, Matthew (2007). "Factors influencing the propensity to cycle to work". In: Transportation Research Part A: Policy and Practice 41.4, pp. 339-350.

Watts, Nick, Amann, Markus, Arnell, Nigel, Ayeb-Karlsson, Sonja, Belesova, Kristine, Boykoff, Maxwell, Byass, Peter, Cai, Wenjia, Campbell-Lendrum, Diarmid, Capstick, Stuart, et al. (2019). "The 2019 report of The Lancet Countdown on health and climate change: ensuring that the health of a child born today is not defined by a changing climate". In: The Lancet 394.10211, pp. 1836-1878.

West, Sarah E and Williams III, Roberton C (2007). "Optimal taxation and cross-price effects on labor supply: estimates of the optimal gas tax". In: Journal of public Economics 91.3-4, pp. 593-617.

WHO, World Health Organisation (2018). "Top 10 causes of death". URL: https : //www. who.int/news-room/fact-sheets/detail/the-top-10-causes-of-death.

Wolkinger, Brigitte, Haas, Willi, Bachner, Gabriel, Weisz, Ulli, Steininger, Karl W, Hutter, Hans-Peter, Delcour, Jennifer, Griebler, Robert, Mittelbach, Bernhard, Maier, Philipp, et al. (2018). "Evaluating health co-benefits of climate change mitigation in urban mobility". In: International journal of environmental research and public health 15.5 , p. 880.

Woodcock, James, Edwards, Phil, Tonne, Cathryn, Armstrong, Ben G, Ashiru, Olu, Banister, David, Beevers, Sean, Chalabi, Zaid, Chowdhury, Zohir, Cohen, Aaron, et al. (2009). "Public health benefits of strategies to reduce greenhouse-gas emissions: urban land transport". In: The Lancet 374.9705, pp. 1930-1943.

Yang, Lin, Griffin, Simon, Khaw, Kay-Tee, Wareham, Nick, and Panter, Jenna (2017). "Longitudinal associations between built environment characteristics and changes in active commuting". In: BMC public health 17.1, p. 458.

Zamir, Eyal and Teichman, Doron (2014). "The Oxford handbook of behavioral economics and the law". Oxford Handbooks. 


\section{A Mathematical Appendix.}

\section{A.1 Derivation of the optimal fuel tax $t^{f}$}

We derive the optimal fuel tax in two steps. First, we consider the consumer's optimisation problem. We define $V$ as the consumer's maximised value function, and determine the first-order conditions corresponding to the solution of this value function. Next, we determine the optimal fuel tax by computing the total derivative of $V$ with respect to the tax on fuel, $d V / d t^{f}$. Setting this term equal to zero then allows us to obtain Equation (13) as detailed below.

\section{A.1.1 Consumer optimisation problem}

The consumer maximises (1) with respect to (2)-(10). As described in the text, it takes pollution $P$, measures for congestion $\pi$ and a large part of the accident risk as given. Instead of considering actual health (7), it considers perceived health (8). This allows us to define the following maximised value function:

$$
\begin{gathered}
V \equiv \operatorname{Max}_{C, F, H, M^{a c}, O, L}\left\{u\left(\psi\left(C, M, T^{i n}, T^{a c}, G\right), N\right)-\varphi(P)-\delta(A)+\xi\left(Q^{p e r}\right)\right. \\
+\mu_{M}\left[M^{i n}+M^{a c}-M\right]+\mu_{M^{i n}}\left[\chi(F, H)-M^{i n}\right]+\mu_{T^{i n}}\left[\pi^{i n}\left(\bar{M}^{i n}\right) M^{i n}-T^{i n}\right] \\
+\mu_{T^{a c}}\left[\pi^{a c} M^{a c}-T^{a c}\right]+\mu_{A}\left[A^{i n}\left(\bar{M}^{i n}, M^{i n}\right)+A^{a c}\left(M^{a c}, \bar{M}^{i n}, \bar{M}^{a c}\right)-A\right] \\
+\mu_{Q^{p e r}}\left[\omega Q\left(M^{a c}, O\right)+\bar{Q}-Q^{p e r}\right]+\mu_{I}\left[w\left(1-t^{l}\right) L-C-\left(p^{f}+t^{f}\right) F-p^{h} H-p^{o} O-S^{a c}\right] \\
\left.+\mu_{S}\left[S\left(M^{a c}\right)-S^{a c}\right]+\mu_{L}\left[\bar{L}-L-N-T^{i n}-T^{a c}\right]\right\}, \quad(\mathrm{A} .1)
\end{gathered}
$$


with corresponding first-order conditions

$$
\begin{gathered}
u_{\psi} \psi_{C}-\mu_{I}=0, \\
u_{\psi} \psi_{M}-\mu_{M}=0, \\
-\delta_{A}-\mu_{A}=0, \\
\mu_{M}-\mu_{M^{i n}}+\mu_{T^{i n}} \pi^{i n}+\mu_{A} A_{M^{i n}}^{i n}=0, \\
\mu_{M}+\mu_{T^{a c}} \pi^{a c}+\mu_{A} A_{M^{a c}}^{a c}+\mu_{Q} \omega Q_{M^{a c}}+\mu_{S} S_{M^{a c}}=0, \\
u_{\psi} \psi_{T^{i n}}-\mu_{T^{i n}}-\mu_{L}=0, \\
u_{\psi} \psi_{T^{a c}}-\mu_{T^{a c}}-\mu_{L}=0, \\
\mu_{M^{i n}} \chi_{F}-\mu_{I}\left(p^{f}+t^{f}\right)=0, \\
\mu_{M^{i n}} \chi_{H}-\mu_{I} p^{h}=0, \\
\xi_{Q}-\mu_{Q}=0 \\
\mu_{Q} \omega Q_{O}-\mu_{I} p^{o}=0, \\
-\mu_{I}-\mu_{S}=0, \\
u_{N}-\mu_{L}=0 \\
-\mu_{L}+\mu_{I} w\left(1-t^{l}\right)=0 .
\end{gathered}
$$

\section{A.1.2 Optimal taxation}

The optimal fuel tax is implicitly determined by $d V / d t^{f}=0$, taking into account that $t^{l}$ is determined through (11), and that in equilibrium $\bar{M}^{i n}=M^{i n}, \bar{M}^{a c}=M^{a c}, \bar{F}=F$, and $\tilde{Q}=(1-\omega) Q$. From (A.1) and (A.2)-(A.15) we then obtain

$$
\begin{aligned}
\frac{d V}{d t^{f}}=\left[\mu_{T^{i n}}\right. & \left.\pi_{\bar{M}^{i n}}^{i n} \chi_{F} M^{i n}-\delta_{A}\left[A_{\bar{M}^{i n}}^{i n}+A_{\bar{M}^{i n}}^{a c}\right] \chi_{F}-\varphi_{P}\left[P_{\bar{F}}^{f}+P_{\bar{M}^{i n}}^{m} \chi_{F}\right]+\mu_{I} t^{f}\right] \frac{d F}{d t^{f}} \\
+ & {\left[\mu_{T^{i n}} \pi_{\bar{M}^{i n}}^{i n} M^{i n} \chi_{H}-\delta_{A}\left[A_{\bar{M}^{i n}}^{i n}+A_{\bar{M}^{i n}}^{a c}\right] \chi_{H}-\varphi_{P} P_{\bar{M}^{i n}}^{m} \chi_{H}\right] \frac{d H}{d t^{f}} } \\
& +\left[-\delta_{A} A_{\bar{M}^{a c}}^{a c}+\xi_{Q}(1-\omega) Q_{M^{a c}}\right] \frac{d M^{a c}}{d t^{f}}+\xi_{Q}(1-\omega) Q_{O} \frac{d O}{d t^{f}}+\mu_{I} w t^{l} \frac{d L}{d t^{f}}
\end{aligned}
$$

Further rearranging this term and using $\frac{d M^{i n}}{d t^{f}}=\chi_{F} \frac{d F}{d t^{f}}+\chi_{H} \frac{d H}{d t^{f}}$ and $\frac{d Q}{d t^{f}}=Q_{M^{a c}} \frac{d M^{a c}}{d t^{f}}+$ $Q_{O} \frac{d O}{d t^{f}}$, we obtain

$$
\begin{aligned}
\frac{1}{\mu_{I}} \frac{d V}{d t^{f}}=\left[t^{f}-\frac{\varphi_{P}}{\mu_{I}} P_{\bar{F}}^{f}\right] \frac{d F}{d t^{f}}+ & {\left[\frac{\mu_{T^{i n}}}{\mu_{I}} \pi_{\bar{M}^{i n}}^{i n} M^{i n}-\frac{\delta_{A}}{\mu_{I}}\left[A_{\bar{M}^{i n}}^{i n}+A_{\bar{M}^{i n}}^{a c}\right]-\frac{\varphi_{P}}{\mu_{I}} P_{\bar{M}^{i n}}^{m}\right] \frac{d M^{i n}}{d t^{f}} } \\
& +\left[-\frac{\delta_{A}}{\mu_{I}} A_{\bar{M}^{a c}}^{a c}\right] \frac{d M^{a c}}{d t^{f}}+(1-\omega) \frac{\xi_{Q}}{\mu_{I}} \frac{d Q}{d t^{f}}+w t^{l} \frac{d L}{d t^{f}} . \quad(\mathrm{A} .16)
\end{aligned}
$$


Equation (A.16) is a generalisation of Equation (2.9) in Parry and Small (2004), taking into account active travel decisions. To find the optimal fuel tax we then set (A.16) equal to zero, and isolate $t^{f}$. We obtain

$$
\begin{aligned}
t^{f *}=Z^{P_{\bar{F}}}+\left[Z^{C}+Z^{A_{\bar{M}} i n}\right. & \left.+Z^{P_{\bar{M}^{i n}}}\right]\left(\frac{-d M^{i n}}{d t^{f}} / \frac{-d F}{d t^{f}}\right)+Z^{A_{\bar{M}^{a c}}}\left(\frac{-d M^{a c}}{d t^{f}} / \frac{-d F}{d t^{f}}\right) \\
& -(1-\omega) \tilde{Z}^{Q}\left(\frac{-d Q}{d t^{f}} / \frac{-d F}{d t^{f}}\right)-w t^{l}\left(\frac{-d L}{d t^{f}} / \frac{-d F}{d t^{f}}\right), \quad \text { (A }
\end{aligned}
$$

where we define

$$
\begin{gathered}
Z^{P_{\bar{F}}} \equiv \frac{\varphi_{P}}{\mu_{I}} P_{\bar{F}}^{f} ; Z^{P_{\bar{M}^{i n}}} \equiv \frac{\varphi_{P}}{\mu_{I}} P_{\bar{M}^{i n}}^{m} ; Z^{A_{\bar{M}^{i n}}} \equiv \frac{\delta_{A}}{\mu_{I}}\left[A_{\bar{M}^{i n}}^{i n}+A_{\bar{M}^{i n}}^{a c}\right] ; \\
Z^{A_{\bar{M}^{a c}}} \equiv \frac{\delta_{A}}{\mu_{I}} A_{\bar{M}^{a c}}^{a c} ; \tilde{Z}^{Q} \equiv \frac{\xi_{Q}}{\mu_{I}} \text {, and } Z^{C} \equiv \Gamma^{i n} \pi_{\bar{M}^{i n}}^{i n} M^{i n}
\end{gathered}
$$

To obtain $Z^{C}$, we use (A.7) and (A.15), and define $\Gamma^{i n} \equiv w\left(1-t^{l}\right)-\psi_{T^{i n}} / \psi_{C}$. Equation (A.17) can in turn be expressed as

$$
t^{f *}=M E C-w t^{l}\left(\frac{-d L}{d t^{f}} / \frac{-d F}{d t^{f}}\right),
$$

with

$$
\begin{gathered}
M E C \equiv Z^{P_{\bar{F}}}+\left[Z^{C}+Z^{A_{\bar{M}}^{i n}}+Z^{P_{\bar{M}} i n}\right] \beta^{M^{i n}} \frac{M^{i n}}{F}+\left[Z^{A_{\bar{M}} a c}-(1-\omega) Z^{Q}\right] \beta^{M^{a c}} \frac{M^{a c}}{F} \\
\beta^{M^{i n}} \equiv \frac{\eta^{M^{i n} F}}{\eta^{F F}} ; \beta^{M^{a c}} \equiv \frac{\eta^{M^{a c} F}}{\eta^{F F}} ; Z^{Q} \equiv \frac{\xi_{Q}}{\mu_{I}} Q_{M^{a c}}
\end{gathered}
$$

where $\eta^{X F}$ is the fuel price elasticity of $X \in\left\{M^{i n}, M^{a c}\right\}$, and we impose $d O / d t^{f}=0$.

By linear homogeneity, $M^{i n}=\chi_{F} F+\chi_{H} H$. Then, using (A.3)-(A.5), (A.7), (A.9), (A.10) and (A.15) we obtain

$$
\frac{u_{M}}{\mu_{I}}=p^{M^{i n}},
$$

with $u_{M} \equiv u_{\psi} \psi_{M}, p^{M^{i n}} \equiv\left[\left(p^{f}+t^{f}\right) \alpha^{F}+p^{h} \alpha^{H}\right]+\Gamma^{i n} \pi^{i n}+\Lambda^{i n}, \alpha^{F} \equiv F / M^{i n}, \alpha^{H} \equiv$ $H / M^{i n}$, and $\Lambda^{i n} \equiv \frac{\delta_{A} A_{M^{i n}}^{i n}}{u_{\psi} \psi_{C}}$. Similarly, from (A.2), (A.3), (A.4), (A.6), (A.8), (A.11), (A.13) and (A.15) we can write

$$
\frac{u_{M}}{\mu_{I}}=p^{M^{a c}},
$$

with $p^{M^{a c}} \equiv S_{M^{a c}}+\Gamma^{a c} \pi^{a c}+\Lambda^{a c}-\Omega^{Q}, \Gamma^{a c} \equiv w\left(1-t^{l}\right)-\frac{\psi_{T} a c}{\psi_{C}}, \Lambda^{a c} \equiv \frac{\delta_{A} A_{M}^{a c} a c}{u_{\psi} \psi_{C}}$, and $\Omega^{Q} \equiv \frac{\xi_{Q}}{u_{\psi} \psi_{C}} \omega Q_{M^{a c}}$. From the perspective of the consumer, $p^{M^{i n}}$ and $p^{M^{a c}}$ denote the 
(minimised) effective price of inactive and active travel, respectively. As in Parry and Small (2004), the homogeneity assumption will ensure that we can write $\alpha^{F}\left(t^{f}\right)$ and $\alpha^{H}\left(t^{f}\right)$. Repeated substitutions using (3), (9), (10), the first order conditions and (A.19) and (A.20) then allow us to write the following demand functions

$$
\begin{array}{cr}
C=C\left(p^{M^{i n}}, t^{l}\right) ; & L=L\left(p^{M^{i n}}, t^{l}\right) ; \\
M^{i n}=M^{i n}\left(p^{M^{i n}}, t^{l}\right) ; & M^{a c}=M^{a c}\left(p^{M^{i n}}, t^{l}\right) ; \\
F=F\left(p^{M^{i n}}, t^{l}, t^{f}\right)=\alpha^{F}\left(t^{f}\right) M^{i n}\left(p^{M^{i n}}, t^{l}\right) ; & \\
H=H\left(p^{M^{i n}}, t^{l}, t^{f}\right)=\alpha^{H}\left(t^{f}\right) M^{i n}\left(p^{M^{i n}}, t^{l}\right) . &
\end{array}
$$

where the last two follow from the definition of $\alpha^{F}$ and $\alpha^{H}$. For prices we can similarly write

$$
p^{M^{i n}}=p^{M^{i n}}\left(t^{f}, \pi^{i n}, t^{l}\right) ; p^{M^{a c}}=p^{M^{a c}}\left(t^{f}, \pi^{i n}, t^{l}\right)
$$

The demand and price functions (A.21) and (A.22) are equivalent to expressions (B3a) and (B3b) in Parry and Small (2004). The remainder of the derivations then similarly follows Parry and Small (2004). First, from (A.21) and (A.22), we can write $L\left(t^{f}, \pi^{i n}, t^{l}\right)$. Then

$$
\frac{d L}{d t^{f}}=\frac{\partial L}{\partial t^{f}}+\frac{\partial L}{\partial \pi^{i n}} \frac{d \pi^{i n}}{d t^{f}}+\frac{\partial L}{\partial t^{l}} \frac{d t^{l}}{d t^{f}}
$$

Now from (11), we have $w L d t^{l}+w t^{l} d L+F d t^{f}+t^{f} d F=0$, which gives

$$
\frac{d t^{l}}{d t^{f}}=-\frac{F+t^{f} \frac{d F}{d t^{f}}+w t^{l} \frac{d L}{d t^{f}}}{w L}
$$

Combining (A.24) and (A.23) then allows us to write

$$
\frac{d t^{l}}{d t^{f}}=-\frac{F+t^{f} \frac{d F}{d t^{f}}+w t^{l}\left[\frac{\partial L}{\partial t^{f}}+\frac{\partial L}{\partial \pi^{i n}} \frac{d \pi^{i n}}{d t^{f}}\right]}{w\left[L+t^{l} \frac{\partial L}{\partial t^{l}}\right]}
$$

Substituting (A.25) into (A.23) and multiplying by $t^{l}$ then yields

$$
t^{l} \frac{d L}{d t^{f}}=\frac{-t^{l} \frac{\partial L}{\partial t^{l}}}{w\left[L+t^{l} \frac{\partial L}{\partial t^{l}}\right]}\left[t^{f} \frac{d F}{d t^{f}}\right]+\frac{t^{l}}{w\left[L+t^{l} \frac{\partial L}{\partial t^{l}}\right]}\left[w \frac{\partial L}{\partial t^{f}} L-\frac{\partial L}{\partial t^{l}} F+w L \frac{\partial L}{\partial \pi^{i n}} \frac{d \pi^{i n}}{d t^{f}}\right] .
$$

Now define $M E B \equiv \frac{-\frac{\partial L}{\partial t} \frac{t^{l}}{L}}{1+\frac{\partial L}{\partial t^{l}} \frac{t^{l}}{L}}$, and let $\varepsilon_{L L}$ denote the uncompensated labour supply elasticity: $\varepsilon_{L L} \equiv \frac{\partial L}{\partial\left[\left(1-t^{l}\right) w\right]} \frac{\left(1-t^{l}\right) w}{L}=\frac{\partial L}{\partial t^{l}} \frac{\partial t^{l}}{\partial\left(1-t^{l}\right) w} \frac{\left(1-t^{l}\right) w}{L}$. Then $M E B_{L}=\frac{\frac{t^{l}}{1-t^{l}} \varepsilon_{L L}}{1-\frac{t^{l}}{1-t^{l}} \varepsilon_{L L}}$, 
which we use in (A.26) to obtain

$$
w t^{l} \frac{d L}{d t^{f}}=M E B\left[t^{f} \frac{d F}{d t^{f}}\right]-\frac{M E B}{\partial L / \partial t^{l}}\left[w \frac{\partial L}{\partial t^{f}} L-\frac{\partial L}{\partial t^{l}} F+w L \frac{\partial L}{\partial \pi^{i n}} \frac{d \pi^{i n}}{d t^{f}}\right] .
$$

Next consider the second term in brackets in (A.27). Then $t^{f}$ and $\pi$ only affect $L$ through $p^{M^{i n}}$ (consider (A.21) and (A.22)). So

$$
\frac{\partial L}{\partial t^{f}}=\frac{\partial L}{\partial p^{M^{i n}}} \frac{\partial p^{M^{i n}}}{\partial t^{f}}=\frac{\partial L}{\partial p^{M^{i n}}} \alpha^{F}
$$

and

$$
\frac{\partial L}{\partial \pi^{i n}}=\frac{\partial L}{\partial p^{M^{i n}}} \frac{\partial p^{M^{i n}}}{\partial \pi^{i n}}=\frac{\partial L}{\partial p^{M^{i n}}} \Gamma^{i n}
$$

Next, from (3),

$$
\frac{d \pi^{i n}}{d t^{f}}=\frac{\partial \pi^{i n}}{\partial M^{i n}} \frac{d M^{i n}}{d t^{f}} .
$$

In turn, $\frac{\partial L^{c}}{\partial p^{M^{i n}}}=\frac{\partial L}{\partial p^{M^{i n}}}+\frac{\partial L}{\partial I} \frac{\partial I}{\partial p^{M^{i n}}}$, where $I=w\left(1-t^{l}\right) L$ denotes income and the superscript $c$ denotes a compensated coefficient. Then we obtain from (A.21):

$$
\frac{\partial L}{\partial p^{M^{i n}}}=\frac{\partial L^{c}}{\partial p^{M^{i n}}}-\frac{\partial L}{\partial I} M^{i n} ; \frac{\partial L}{\partial t^{l}}=\frac{\partial L^{c}}{\partial t^{l}}-\frac{\partial L}{\partial I} w L
$$

The Slutsky symmetry property gives $\frac{\partial L^{c}}{\partial p^{M^{i n}}}=-\frac{\partial M^{i n, c}}{\partial\left(1-t^{l}\right) w}$. Note again that $\frac{\partial M^{i n, c}}{\partial\left(1-t^{l}\right) w}=$ $\frac{\partial M^{i n, c}}{\partial t^{l}} \frac{\partial t^{l}}{\partial\left(1-t^{l}\right) w}=-\frac{\partial M^{i n, c}}{\partial t^{l}} w^{-1}$, SO

$$
\frac{\partial L^{c}}{\partial p^{M^{i n}}}=\frac{\partial M^{i n, c}}{\partial t^{l}} w^{-1}
$$

Next, leisure is weakly separable in utility. So when $t^{l}$ changes, it affects consumption and demand only through disposable income. This gives

$$
\frac{\partial M^{i n, c}}{\partial t^{l}}=\frac{\partial M^{i n, c}}{\partial I} w\left(1-t^{l}\right) \frac{\partial L^{c}}{\partial t^{l}}
$$

where $w\left(1-t^{l}\right) \partial L^{c} / \partial t^{l}$ is the change in disposable income following a compensated increase in the labour tax. Then we can use (A.28)-(A.33) to find

$$
w \frac{\partial L}{\partial t^{f}} L-\frac{\partial L}{\partial t^{l}} F=\left(\eta^{M I}-1\right) \frac{\partial L^{c}}{\partial t^{l}} F
$$


and

$$
w L \frac{\partial L}{\partial \pi^{i n}} \frac{d \pi^{i n}}{d t^{f}}=\left[\eta^{M^{i n} I} \frac{\partial L^{c}}{\partial t^{l}}-w L \frac{\partial L}{\partial I}\right] Z^{C} \frac{d M^{i n}}{d t^{f}},
$$

with $\eta^{M I} \equiv \frac{\partial M^{i n, c}}{\partial I} \frac{I}{M^{i n}}$. Substituting (A.34) and (A.35) back in (A.27) then gives

$w t^{l} \frac{d L}{d t^{f}}=M E B\left[t^{f} \frac{d F}{d t^{f}}\right]-\frac{M E B}{\varepsilon_{L L}}\left[\varepsilon_{L L}^{c}\left(\eta^{M^{i n} I}-1\right) F+\left[\varepsilon_{L L}-\varepsilon_{L L}^{c}\left(1-\eta^{M^{i n} I}\right)\right] Z^{C} \frac{d M^{i n}}{d t^{f}}\right]$

where we use the compensated labour elasticity $\varepsilon_{L L}^{c}=-\frac{\partial L^{c}}{\partial t^{l}} \frac{1-t^{l}}{L}=-\frac{\partial L^{c}}{\partial t^{l}} \frac{t^{l}}{L} \frac{1-t^{l}}{t^{l}}$, and, from the Slutsky equation, $\varepsilon_{L L}=\varepsilon_{L L}^{c}+\eta_{L I}$. We then substitute (A.36) into (A.18) to obtain (13).

\section{B Parametrisation, further details}

\section{B.1 Additional parameters}

Table B.1 lists additional values used in our calculations of Equation (13), but not previously specified in Table 1.

Table B.1: Remaining parameter values

\begin{tabular}{lrr}
\hline \hline & US & UK \\
Parameter & Central value & Central value \\
\hline Number of active miles travelled per person per year, $M^{a c}$ & 267 & 740 \\
Number of vehicle miles travelled per person per year, $M^{i n}$ & 10,307 & 9124 \\
& & \\
Uncompensated labour supply, $\varepsilon_{L L}$ & 0.2 & 0.2 \\
Compensated labour supply, $\varepsilon_{L L}^{c}$ & 0.35 & 0.35 \\
Producer price of gasoline, $p^{f}$ & 186 & 186 \\
Tax on labour, $t_{L}$ & 0.318 & 0.31 \\
\hline
\end{tabular}

\section{B.2 Elasticities}

Tables B.2, B.3 and B.4 provide an overview of the elasticity of fuel, inactive, and active miles travelled with respect to the fuel price established in the literature. These elasticities capture the extent to which fuel consumption, inactive miles travelled (VMT), and active miles travelled change in response to fuel prices. We use these values to parametrise our model as explained in Section 3.1.1. Similarly, Table B.5 lists the literature estimates for the income elasticity of inactive travel, which captures the response of inactive miles travelled to income changes. 
Table B.2: Fuel price elasticity, $\eta^{F F}$

\begin{tabular}{lrrll}
\hline \hline Country & Value & \multicolumn{1}{l}{ Range } & Notes & Source \\
\hline OECD & -0.3 & -0.6 to -0.8 & short run and long run, resp. & Graham and Glaister (2002) \\
UK and US & -0.55 & -0.3 to -0.9 & & Parry and Small (2005) \\
US & -0.21 & -0.21 to -0.75 & short run & Hughes et al. (2006) \\
US & -0.43 & & & Small, Van Dender, et al. (2007) \\
US & -0.46 & -0.1 & & Davis and Kilian (2011) \\
US & -0.3 & & & Dahl (2012) \\
UK & -0.33 & & & Dahl (2012) \\
UK & -0.6 & & & Fouquet (2012) \\
US & -0.31 & & Hesponse to change in tax size & Dieler et et al. (2015) \\
Europe & -0.82 & & & Coglianese et al. (2017) \\
US & -0.37 & & Levin et al. (2017) \\
US & -0.27 & -0.27 to -0.35 & & Gillingham and Munk-Nielsen (2019) \\
Denmark & -0.3 & up to -0.87 & &
\end{tabular}

The only direct estimate of a cross-elasticity of active modes of travel (walking and cycling) with respect to fuel price, $\eta^{M^{a c} F}$, we identified is a 1999 report summarising the research of several European studies (Hague Publishing et al., 1999). To our knowledge, no cross-elasticity estimates for the US exist in the literature. This poses two problems: first, the data on cross-elasticities is old, and cultural differences may mean that people's behaviour is more (less) elastic towards other modes of travel, including bike sharing, ride-hailing services such as Uber, or electric non-active modes such as e-scooters (see e.g. Shipman (2019)). Second, the data is context-specific to higher density European cities.

To adjust for this gap in the literature, we additionally consider the cross-elasticity of public transport with respect to the fuel price. Although we recognise that the relationship between active travel, public transport, and car use is likely to be different in the UK and US, we use the same values of $\eta^{M^{a c} F}$ for both countries. This is because of the limited number of studies estimating this value.

For the income elasticity of inactive travel, $\eta^{M^{i n} I}$, we consider the following. Direct estimates of $\eta^{M^{i n} I}$ can be found in Small, Van Dender, et al. (2007), Santos and Catchesides (2005) and Fouquet (2012). Additionally, and akin to Parry and Small (2005), we consider estimates for the income elasticity of fuel use (Mattioli et al., 2018; West and Williams III, 2007). This approach is justified by Johansson and Schipper (1997), who found that the income elasticity of fuel use and miles travelled were approximately equal. 
Table B.3: Fuel price elasticity of inactive miles travelled (VMT), $\eta^{M^{i n} F}$

\begin{tabular}{lrrll}
\hline \hline Country & Value & \multicolumn{1}{l}{ Range } & Notes & Source \\
\hline OECD & -0.3 & -0.15 to -0.3 & short run and long run, resp. & Graham and Glaister (2002) \\
UK and US & -0.4 & $0.2-0.6$ & Parry and Small (2005) \\
US & -0.1 & & Small, Van Dender, et al. (2007) \\
Germany & -0.45 & & Frondel and Vance (2013) \\
California & -0.147 & 0.041 to -0.288 & Knittel and Sandler $(2013)$ \\
Denmark & -0.32 & -0.32 to -0.45 & De Borger et al. (2016) \\
UK & -0.301 & -0.1803 to -0.417 & Cerruti et al. (2019) \\
US & -0.3 & -0.05 to -0.3 & Gillingham and Munk-Nielsen $(2019)$ \\
\hline
\end{tabular}

Table B.4: Cross-elasticity of active travel and public transport (PT) use, $\eta^{M^{a c} F}$

\begin{tabular}{|c|c|c|c|c|}
\hline Type & Country & Value & Notes & Source \\
\hline $\mathrm{PT}$ & Australia & 0.104 to 0.291 & & Hensher and King (1998) \\
\hline Walking and cycling & Europe & 0.13 & & Hague Publishing et al. (1999) \\
\hline PT & Europe & 0.14 & & Hague Publishing et al. (1999) \\
\hline PT - transit general & US & 0.12 & & Currie and Phung (2007) \\
\hline PT - light rail & US & 0.27 to 0.38 & & Currie and Phung (2007) \\
\hline PT - buses & US & 0.04 & & Currie and Phung (2007) \\
\hline PT & US & 0.24 & & Haire and Machemehl (2007) \\
\hline PT & US & 0.4 & short term & Holmgren (2007) \\
\hline PT & Australia & 0.22 & & Currie and Phung (2008) \\
\hline PT & US & 0.366 & Upward trend in elasticities & Lane (2008) \\
\hline PT & US & 0.08 to 0.16 & (medium-) small cities only & Mattson (2008) \\
\hline PT & South Korea & 0.32 & & Lee et al. (2009) \\
\hline PT - rail, regional & US & 0.27 to 0.38 & & Maley and Weinberger (2009) \\
\hline PT - local, bus & US & 0.15 to 0.23 & & Maley and Weinberger (2009) \\
\hline $\mathrm{PT}$ - commuter rail & 218 US cities & -0.012 to 0.213 & Upward trend in elasticities $2002-2008$ & Blanchard (2009) \\
\hline PT - light rail & 218 US cities & -0.103 to 0.507 & elasticities increased 2002-2008 & Blanchard (2009) \\
\hline PT & & 0.116 & & Iseki, Ali, et al. (2014) \\
\hline
\end{tabular}

Table B.5: Income elasticity of inactive travel, $\eta^{M^{i n} I}$

\begin{tabular}{lrrl}
\hline \hline Country & Value & \multicolumn{1}{l}{ Range } & Source \\
\hline UK & 0.8 & $0.4-1.2$ & Parry and Small (2005) \\
US & 0.6 & $0.3-0.9$ & Parry and Small (2005) \\
UK & 0.4 & 0.0681 to 0.6335 & Santos and Catchesides (2005) \\
US & 0.02 & & West and Williams III (2007) \\
US & 0.53 & & Small, Van Dender, et al. (2007) \\
UK & 0.8 & & Fouquet (2012) \\
UK high income & 0.62 & 0.54 to 0.7 & Mattioli et al. (2018) \\
UK low income & 0.56 & 0.36 to 0.75 & Mattioli et al. (2018) \\
\hline
\end{tabular}




\section{B.3 External cost of fuel $\left(\mathrm{CO}_{2}\right)$ pollution, $Z^{P_{\bar{F}}}$}

Table B.6 provides an overview of literature estimates for the social cost of carbon. We assign the greatest weight to the recent studies by Pindyck (2019) and Hänsel et al. (2020), which both rely on interviews conducted with experts in the field and their view regarding the appropriate value of the SCC.

Table B.6: Social cost of carbon estimates literature overview

\begin{tabular}{rrl}
\hline \hline USD 2017, per tonne $\mathrm{CO}_{2}$ & Plausible SCC range & Source \\
\hline 91.8 & $2.6-367$ & Parry and Small (2005) \\
78.8 & $0-297.6$ & Tol (2011) \\
900 & up to 1500 & Ackerman and Stanton (2012) \\
49.7 & $14.2-73.3$ & Environmental Protection Agency (2016) \\
40 & $17-84$ & van den Bijgaart et al. (2016) and DICE \\
& & as calculated by OECD (2018) \\
517 & 5274.4 & Adler et al. (2017) \\
92.4 & $46.2-140$ & BEIS (2018) \\
41.3 & $25.4-157.5$ & Nordhaus (2018) \\
417 & $177-805$ & Ricke et al. (2018) \\
319.3 & $253.2-385.4$ & Cai and Lontzek (2019) \\
90 & $80-100$ & Pindyck (2019) \\
96 & $16.2-494.4$ & Hänsel et al. (2020) \\
\hline
\end{tabular}

A selection of the social cost of carbon estimates found in the literature. BEIS (2018) is a UK specific value.

To obtain the externality cost per gallon of fuel used, we need to account for the different fuel $\mathrm{CO}_{2}$ emission intensities, as well as the country-specific average fuel composition. The average emissions intensity of diesel is $8.7 \mathrm{kgCO}_{2} /$ gallon, and 10.1 $\mathrm{kgCO}_{2}$ /gallon for gasoline. The US fuel mix is $98.5 \%$ gasoline, while the UK fuel mix is $55 \%$ gasoline and $45 \%$ diesel. Using a central value for the social cost of carbon of 90 $\$ / \mathrm{tCO}_{2}$, and a low (high) value of 40 (400) $\$ / \mathrm{tCO}_{2}$, we obtain the estimates for $Z^{P_{\bar{F}}}$ as specified in Table 1.

\section{B.4 Marginal value of health through active travel $Z^{Q}$ (HEAT)}

To determine the marginal value of health through active travel increases, $Z^{Q}$, we use estimates from the WHO Health Economic Assessment Tool (HEAT). HEAT is an openaccess online tool for conducting economic assessments of active transport (changes) and their impact on health benefits from physical activity, air pollution, accidents, and effects on carbon emissions. ${ }^{38}$ Importantly, the tool relies on international expert

\footnotetext{
${ }^{38}$ The tool is available on www.heatwalkingcycling.org.
} 
consensus and the methodology is regularly updated to reflect new research evidence and data. The tool can be used for cost-benefit analysis, and requires inputs on baseline levels of active travel, the assessed change in active travel, the time needed to achieve those changes, as well as assumptions regarding substitution away from other forms of exercise. Other (optional) inputs are the discount rate, the value of statistical life (VSL), and the source the information supplied to the model comes from (count data, population survey, modelled data, hypothetical scenario). In its computations, HEAT assumes a linear relationship between active travel increases and health benefits. More details can be found in Section 3.4 of Kahlmeier et al. (2017). ${ }^{39}$

While the tool is not designed for use outside of Europe, ${ }^{40}$ it has been applied to US settings. Examples are Colorado (BBC Consulting, 2017), Arkansas (BBC Consulting, 2018) and Boston (James et al., 2014). We therefore used HEAT for both the UK and the US, and used country-specific values to calibrate the model.

Further details regarding the data inputs we used are given below. Baseline average levels of walking and cycling of 4.8 and 1.2 minutes per day in the UK, and 5.6 and 0.4 for the US. We consider an increase of 5 minutes of activity per person per day for the population aged 20-74, split between the walking and cycling according to current proportions of the two modes. We assume changes materialize over a three year adjustment period, and denote an average of lives saved per year over a 10 year period as our outcome variable of interest. We use 2017 population data from Murphy et al. (2018) for the US, and Patel (2017) for the UK. HEAT requires the user to specify the degree to which increases in active travel crowd out other forms of activity. As evidence suggests that exercise through active travel is additive, rather than crowding out other forms of exercise (Foley et al., 2015; Laeremans et al., 2017; Dons et al., 2018; Castro et al., 2019), we assume that all increases in physical activity are additional. Finally, we maintain the HEAT default parameter values for "mortality relative risk reductions" associated with walking (0.89) and cycling (0.90), which affect the number of lives saved due to a given increase in active travel.

HEAT focuses on mortality reductions due to active travel. A more accurate representation of the health effects of active travel would also account for quality of life effects. Adopting a healthy lifestyle can, for instance, increase the disease-free

\footnotetext{
${ }^{39}$ Discussions of the strengths and limitations of HEAT, and the best methods for economic evaluations of active travel, can be found in Fishman et al. (2015) and Deenihan and Caulfield (2014).

${ }^{40}$ US cities are less dense and have too small shares of walking and cycling (about $0.2 \%$ of total travel) to make a country-wide assessment about the impact of active travel on health. Conversely, Asian cities, though often high-density, have such elevated levels of air pollution exposure that the physical activity relative risk reduction coefficients HEAT uses are not appropriate.
} 
lifetime of an adult by up to 10 years (Li et al., 2020). As HEAT does not include such benefits, we consider it a conservative estimate of the overall health benefits of active travel per mile travelled.

The main output from HEAT is the number of deaths saved through the specified increase in active travel. We use the VSL, which reflects the value society places on a life and is commonly used in cost-benefit analyses, to convert these lives saved to $\$$ amounts. In line with OECD (2012) and updated to end 2017 values, we adopt a US VSL of $\$ 9.26 \mathrm{~m}$; for the UK we use $\$ 4.36 \mathrm{~m}$ (OECD, 2012; Kahlmeier et al., 2017). This approach gives the value of the total number of lives saved due to an increase in active travel by 5 minutes. We finally convert this value to the value of health gained per additional mile of active travel, by dividing by the total increase in active travel, assuming a speed of 15 minutes per mile. This gives a central value of $Z^{Q}$ of $\$ 6.91$ for the US, and $\$ 2.44$ for the UK.

\section{Quantification of second-best results, further details}

\section{C.1 Obtaining the numerical results}

Our quantification of the optimal fuel tax takes into account that the fuel consumption $F$ and miles travelled $M^{i n}$ and $M^{a c}$ depend on the fuel tax level. In other words, we approximate $Z / F$ in (14) by

$$
\frac{Y}{F}=\frac{Z^{0}}{F^{0}}\left(\frac{p^{f}+t_{1}^{f *}}{p^{f}+t^{f 0}}\right)^{\eta^{Z F}-\eta^{F F}}
$$

with $Y \in\left\{M^{i n}, M^{a c}\right\}$, and where $t^{f 0}$ and $Y^{0}$ denote the baseline level of $t^{f}$ and $Y{ }^{41}$ We take labour supply $L$ and labour taxes $t^{l}$ as constant throughout the quantification. While through Equations (10) and (11), changes in time spent travelling and fuel tax revenues may affect labour supply and taxes, this effect is likely minor, and abstracting from this interaction substantially simplifies computations.

We additionally compute a "naïve" tax rate, where we ignore the endogeneity of fuel consumption and miles travelled, fixing those variables at their baseline levels instead. The results of this exercise are presented in Table C.1, and show that calculating the optimal fuel tax at baseline levels lowers the tax level.

\footnotetext{
${ }^{41}$ See also Parry and Small (2005).
} 
Table C.1: Optimal fuel tax rate, fixed fuel consumption and miles travelled

\begin{tabular}{lrr}
\hline Cost, USD cents/gallon & United States & United Kingdom \\
\hline Adjusted Pigouvian tax: & & \\
$\quad$ Pollution, fuel-related, $Z^{P_{\bar{F}}}$ & 91 & 86 \\
Pollution, distance-related, $Z^{P_{\bar{M}}^{i n}} \beta^{M^{i n}} \frac{M^{i n}}{F}$ & 75 & 74 \\
Congestion, $Z^{C} \beta^{M^{i n}} \frac{M^{i n}}{F}$ & 167 & 102 \\
Accidents inactive, $Z^{\bar{A}_{\bar{M}}^{i n}} \beta^{M^{i n}} \frac{M^{i n}}{F}$ & 107 & 33 \\
Accidents active, $Z^{A_{\bar{M}}^{a c}} \beta^{M^{a c}} \frac{M^{a c}}{F}$ & -1.7 & -1.4 \\
Physical inactivity, $(1-\omega) Z^{Q} \beta^{M^{a c}} \frac{M^{a c}}{F}$ & 107 & 104 \\
Adjustment to $M E C_{F}$ for excess burden & -51 & -35 \\
Ramsey tax & 66 & 77 \\
Congestion feedback & -0.8 & 2.8 \\
\hline Optimal fuel tax rate with physical activity, $t_{f}^{*}$ & 560 & 442 \\
Optimal fuel tax rate without physical activity & 462 & 346 \\
Optimal fuel tax rate with physical activity, main specification & 1013 & 454 \\
\hline Current (2017) tax rate & 406 & 55 \\
\hline
\end{tabular}

The second-best optimal fuel tax that does not allow for fuel or mileage related adjustments (fourth row from the bottom) is far lower than the second-best optimal fuel tax with endogenously determined fuel consumption, fuel efficiency, and active and inactive miles travelled (second row from the bottom).

\section{C.2 Quantifying welfare effects}

We follow Parry and Small (2005) and Parry and Small (2004) to obtain a formula for the welfare gain of a marginal tax increase. First, we use the definitions for $Z$ to rewrite (A.16) as

$$
\begin{aligned}
\frac{1}{\mu_{I}} \frac{d V}{d t^{f}}=\left[Z^{P_{\bar{F}}}-t^{f}\right] \frac{-d F}{d t^{f}}+\left[Z^{C}+Z^{A_{\bar{M}^{i n}}}+Z^{P_{\bar{M}^{i n}}}\right] \frac{-d M^{i n}}{d t^{f}}+ \\
{\left[Z^{A_{\bar{M}^{a c}}}\right] \frac{-d M^{a c}}{d t^{f}}-(1-\omega) \tilde{Z}^{Q} \frac{-d Q}{d t^{f}}-w t^{l} \frac{-d L}{d t^{f}} . }
\end{aligned}
$$

Next, assuming that the effect of $t^{f}$ on $Q$ runs through $M^{a c}$ alone, we can write

$$
\begin{aligned}
\frac{1}{\mu_{I}} \frac{d V}{d t^{f}}=\left[Z^{P_{\bar{M}}^{i n}}-t^{f}\right] \frac{-d F}{d t^{f}}+\left[Z^{C}+Z^{A_{\bar{M}^{i n}}}+Z^{P_{\bar{M}}^{i n}}\right] \frac{-d M^{i n}}{d t^{f}}+ \\
{\left[Z^{A_{\bar{M}}^{a c}}-(1-\omega) Z^{Q}\right] \frac{-d M^{a c}}{d t^{f}}-w t^{l} \frac{-d L}{d t^{f}} . }
\end{aligned}
$$

Now use the the definitions of $\eta^{F F} \equiv \frac{d F}{d p_{F}} \frac{p_{F}}{F}, \eta^{M^{i n} F} \equiv \frac{d M^{i n}}{d p_{F}} \frac{p_{F}}{M^{i n}}, \eta^{M^{a c} F} \equiv \frac{d M^{a c}}{d p_{F}} \frac{p_{F}}{M^{a c}}$, $\beta^{M^{i n}}=\eta^{M^{i n} F} / \eta^{F F}$ and $\beta^{M^{a c}}=\eta^{M^{a c} F} / \eta^{F F}$. Then $\frac{-d F}{d t^{f}}=-\frac{d F}{d p_{F}} \frac{p_{F}}{F} \frac{F}{p_{F}}=-\eta_{F F} \frac{F}{p_{F}}$ and, 
using a similar approach for $\frac{-d M^{i n}}{d t^{f}}$, we can write

$$
\begin{aligned}
\frac{1}{\mu_{I}} \frac{d V}{d t^{f}}= & {\left[Z^{P_{\bar{M}^{i n}}}-t^{f}\right]\left(-\eta^{F F} \frac{F}{p^{f}+t^{f}}\right)+\left[Z^{C}+Z^{A_{\bar{M}^{i n}}}+Z^{P_{\bar{M}}^{i n}}\right]\left(-\eta^{M^{i n} F} \frac{M^{i n}}{p^{f}+t^{f}}\right) } \\
& +\left[Z^{A_{\bar{M}^{a c}}}-(1-\omega) Z^{Q}\right]\left(-\eta^{M^{a c} F} \frac{M^{a c}}{p^{f}+t^{f}}\right)-w t^{l} \frac{-d L}{d t^{f}} .
\end{aligned}
$$

Next use (14) to find

$$
\frac{1}{\mu_{I}} \frac{d V}{d t^{f}}=\left[M E C-t^{f}\right]\left(-\frac{F \eta^{F F}}{p^{f}+t^{f}}\right)+w t^{l} \frac{d L}{d t^{f}} .
$$

Note that in Parry and Small (2005), wages $w$ are normalised to 1 . In addition, the (negative) value of $\eta^{F F}$ is expressed in absolute terms. Finally, they define $p^{F}$ as the tax-inclusive fuel price, which in our setting is given by $p^{f}+t^{f}$. In sum, this means that Equation (D1) in Parry and Small (2004) and (C.1) and all subsequent expressions in the derivations are equivalent solutions.

Finally, further substitutions along the lines suggested in Appendix D in Parry and Small (2004) allow us to further rewrite (C.1), as

$$
\frac{1}{\mu_{I}} \frac{d V}{d t^{f}}=\left(-\frac{F \eta^{f f}}{p^{f}+t^{f}}\right)\left(1+M E B_{L}\right)\left[t^{f *}-t^{f}\right] .
$$

\section{C.3 Quantifying changes in mortality}

To quantify the number of lives lost or gained as discussed in Section 4, we used HEAT and followed instructions by Kahlmeier et al. (2017). We parameterise HEAT as described in Section B.4. Further conditions that were specifically calibrated to the US and UK contexts are listed in Table C.2 below.

Table C.2: Country-specific HEAT inputs into welfare change analysis

\begin{tabular}{lrllrll}
\hline \hline \multirow{2}{*}{ Input } & \multicolumn{2}{c}{ US } & & & UK & \\
\cline { 2 - 3 } \cline { 5 - 6 } & Value & Source & Value & Source \\
\hline Traffic conditions & $35 \mathrm{~km} / \mathrm{h}$ & HEAT def., some congestion & & $32 \mathrm{~km} / \mathrm{h}$ & HEAT def., EU av. \\
Air quality, $\mathrm{PM}_{2.5} \mu \mathrm{g} / \mathrm{m}^{3}$ & 7.5 & EPA $(2017)$ & & 10.5 & HEAT def., UK av. \\
Fatalities $/ 100 \mathrm{~m} \mathrm{~km}$, walking & 4.7 & Buehler and Pucher (2017) & & 2.2945 & HEAT def., UK av. \\
Fatalities $/ 100 \mathrm{~m} \mathrm{~km}$, cycling & 9.7 & Buehler and Pucher (2017) & & 2.1377 & HEAT def., UK av. \\
\hline
\end{tabular}

Additional inputs that calibrate the calculations HEAT does to the context of the US and UK. Values labelled "HEAT def." are default values provided by the HEAT tool and are average values that apply specifically to the UK or European context.

HEAT provides risk-specific mortality changes, which we aggregated in to a single 
value in the main text. Table C.3 shows the disaggregation of this value for the change from the current tax levels to the second-best optimal fuel tax levels for both countries.

Table C.3: Country and cause-specific mortality changes, as provided by HEAT

\begin{tabular}{lrr}
\hline \hline & \multicolumn{1}{l}{ US } & \multicolumn{1}{c}{ UK } \\
\cline { 2 - 3 } Cause of death & Value & Value \\
\hline Physical activity & -6457 & -40 \\
Air pollution exposure & 83 & 0.9 \\
Crash risk & 108 & 0.3 \\
\hline
\end{tabular}

Number of lives gained (negative value) or lost (positive value) per country per year, following a change from current to second-best optimal fuel tax levels, $t^{f}$.

\section{C.4 Sensitivity analysis}

The sensitivity analysis was done by applying Latin Hypercube algorithms, implemented by the pse package in $\mathrm{R}$ (Chalom and de Prado, 2015). Latin Hypercube sampling is a method of parameter space exploration and optimisation, and is described in more detail (and compared against other methods, such as individual parameter disturbance and Monte Carlo) in Chalom and de Prado (2015). The results are depicted in Figure 5, which specifies the probabilities that the second-best optimal fuel taxes lie below a pre-specified value.

Figures C.1a and C.1b additionally show the relative influence of each parameter on the optimal fuel tax. More specifically, each Figure shows the partial rank correlation coefficient, defined as the effect of changing one parameter, ceteris paribus, relative to changing any other parameter, ceteris paribus, on the fuel tax. A negative value means that a larger parameter value reduces the size of the optimal fuel tax, and vice versa. From the figure, the external cost of $\mathrm{CO}_{2}, Z^{P_{\bar{F}}}$ and the fuel price elasticity, $\eta^{F F}$ have the greatest effect on the optimal tax, both for the US and the UK. The effect of the external cost of accidents is comparatively small. 


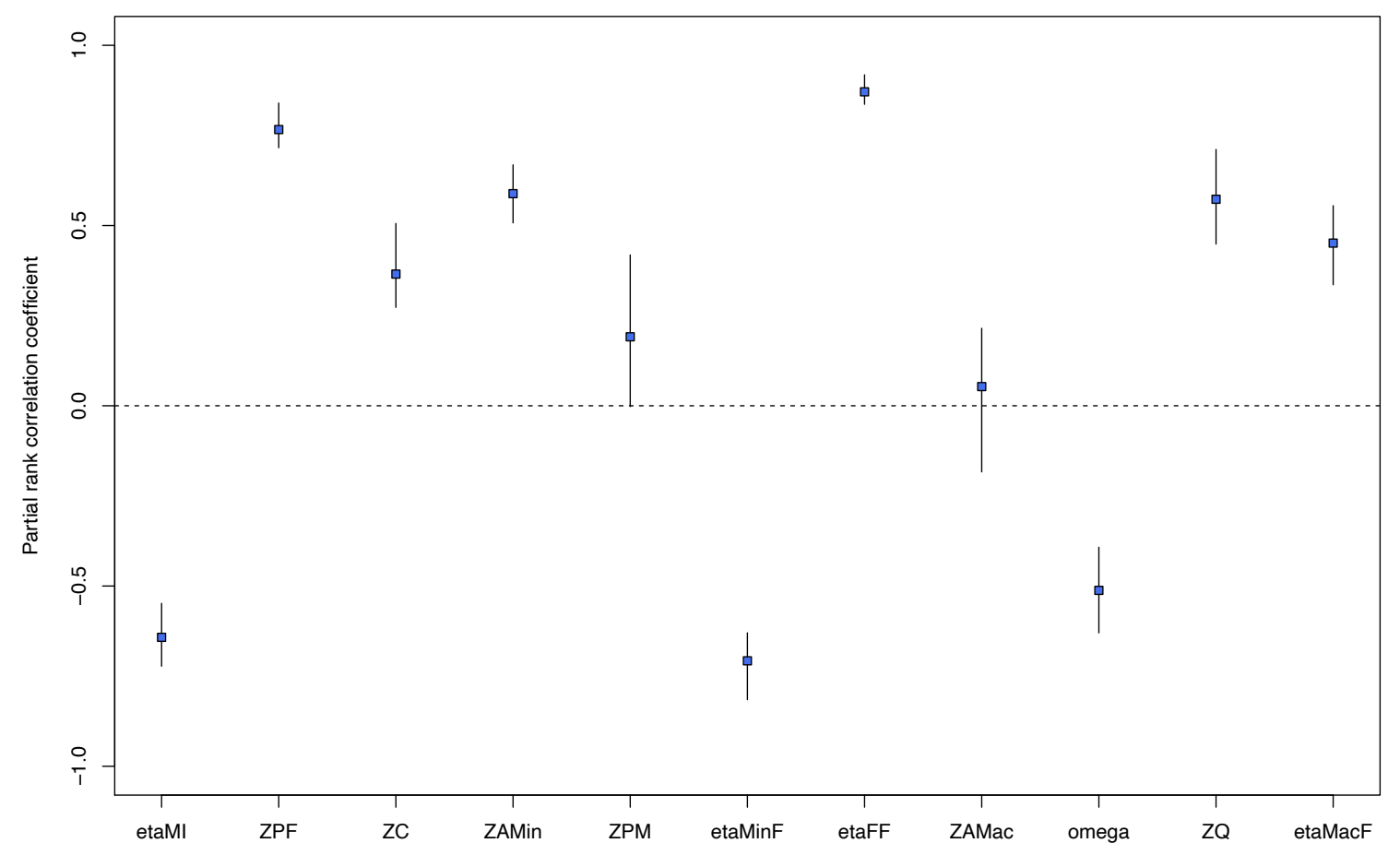

(a) PRCC plot for the US.

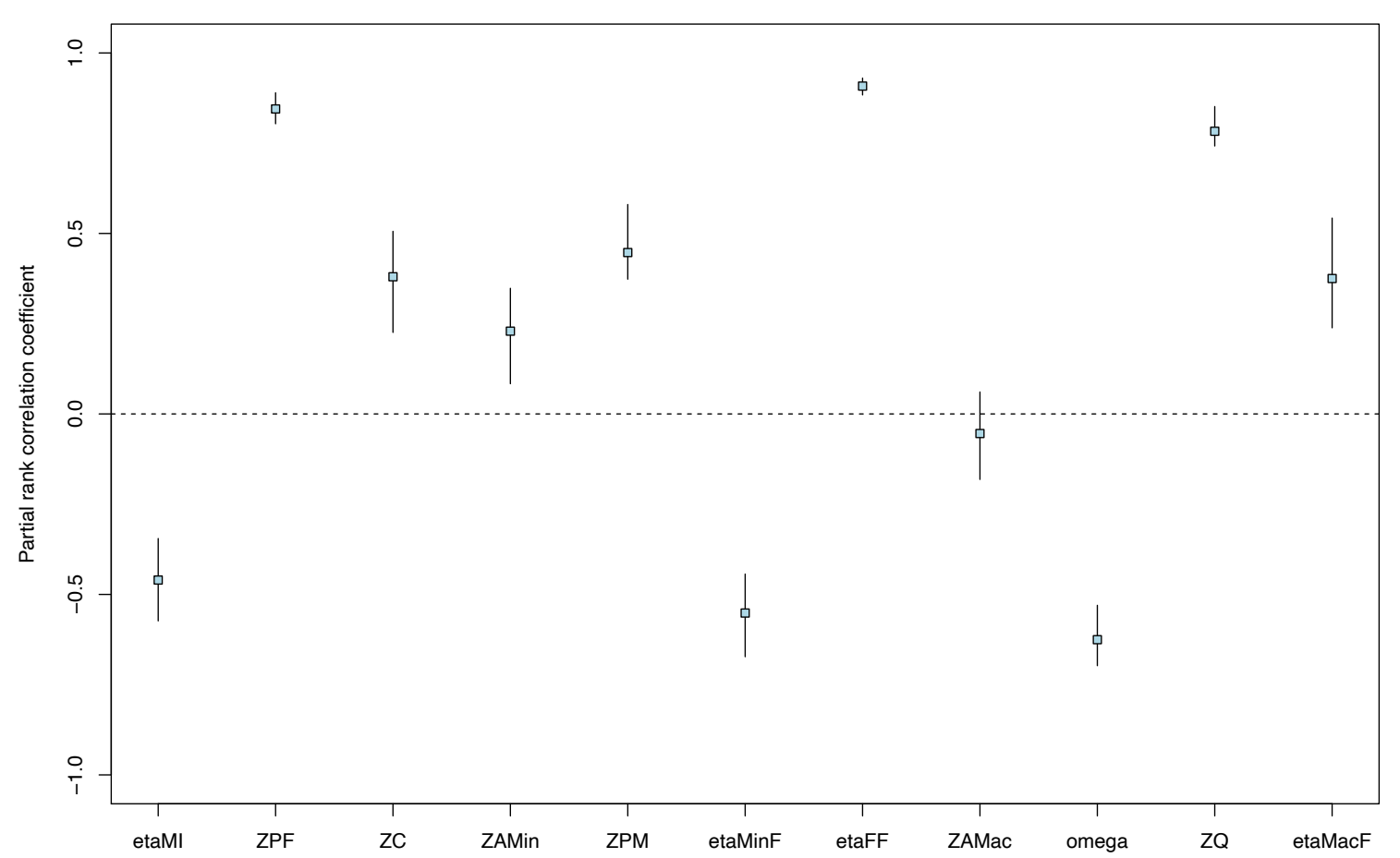

(b) PRCC plot for the UK.

66

Figure C.1: Partial rank correlation coefficient (PRCC) plots showing the relative influence of each parameter on the optimal fuel tax, obtained using Latin Hypercube sensitivity analysis. 